\title{
Versatile electrochemical coatings and surface layers from aqueous methanesulfonic acid
}

\author{
Frank C. Walsh ${ }^{\mathrm{a}, \mathrm{b}}$, Carlos Ponce de León ${ }^{\mathrm{a}, *}$ \\ a Electrochemical Engineering Laboratory, Engineering Sciences, University of Southampton, Highfield, Southampton SO17 1BJ, UK \\ ${ }^{\mathrm{b}}$ National Centre for Advanced Tribology, Engineering Sciences, University of Southampton, Highfield, Southampton SO17 1BJ, UK
}

\section{A R T I C L E I N F O}

Article history:

Received 7 July 2014

Accepted in revised form 4 October 2014

Available online xxxx

\section{Keywords:}

Anodising

Alloys

Conductive polymer

Composite coating

Electrodeposition

Nanostructures

\begin{abstract}
A B S T R A C T
Ever tightening environmental pressure together with the continued need for coatings able to meet challenging service environments have stimulated advances in coating technology. In the case of electrochemical techniques, the classical techniques of electrodeposition and anodising are being upgraded to meet the need for modern surface engineering coatings (including nanostructured films) on metals. A major challenge is to retain conventional processing, including aqueous solutions, simple power supplies and existing electrolyte tanks while using cost effective, 'green' electrolytes. One successful direction has been the emergence of electrolytes based on methanesulfonic acid, MSA which has good electrolytic conductivity and is capable of dissolving many metals as well as acting as a useful medium for dispersion of solids prior to electrophoretic coating. A range of application methods result, including electroplating, anodising and electrophoretic deposition from a stable, aqueous sol. A diverse range of coating materials is emerging, including metals, alloys, porous metal oxide films, conductive polymers and many composites. This review illustrates the usefulness and applications of MSA electrolytes using recent examples from the authors' laboratories and others. Developing coatings, including alternating multilayers of $\mathrm{Sn}$ and $\mathrm{Cu}$, nanostructured metals, hierarchical pores, nanotubular metal oxides and graphene composites are briefly considered. This is a review with 94 references.
\end{abstract}

(c) 2014 Elsevier B.V. All rights reserved.

\section{Contents}

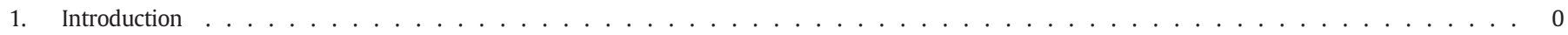

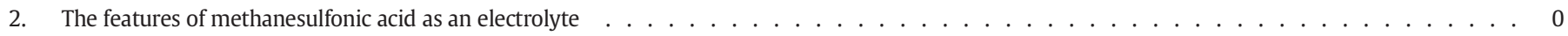

2.1. General properties . . . . . . . . . . . . . . . . . . . . . . . . . . . . 0

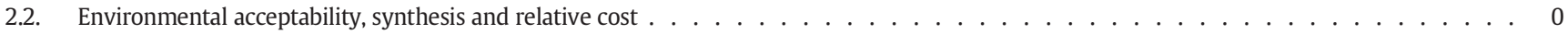

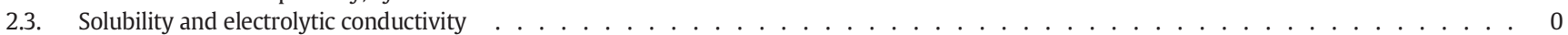

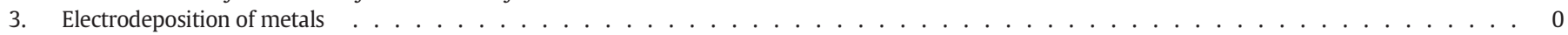

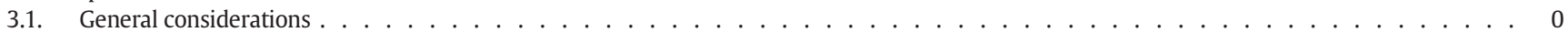

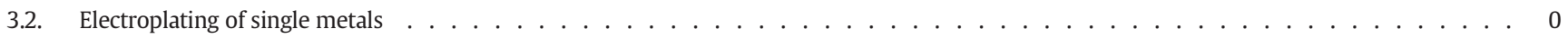

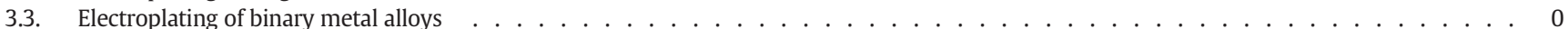

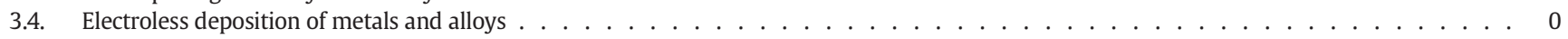

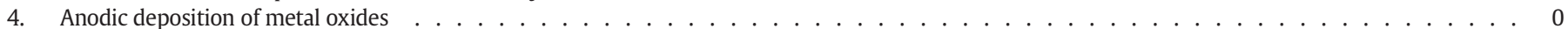

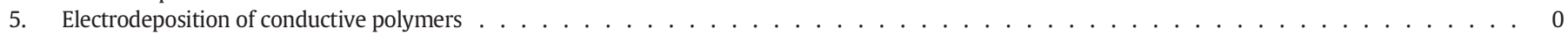

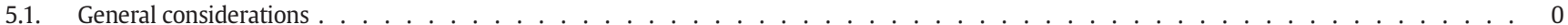

5.2. Electrodeposition of polypyrrole layers . . . . . . . . . . . . . . . . . . . . . . . . . . . . . . . . . . . . . . . . 0

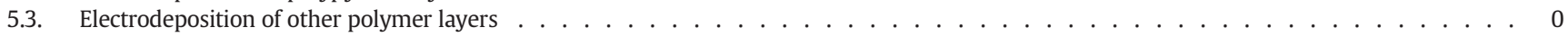

6. Electrodeposition of two-phase and composite coatings . . . . . . . . . . . . . . . . . . . . . . . . . . . . . . 0

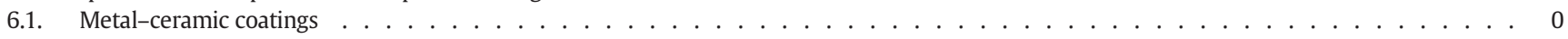

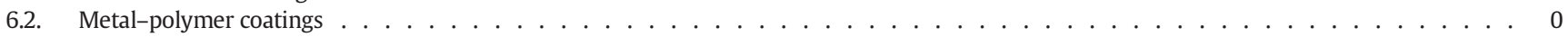

6.3. Polymer-ceramic coatings . . . . . . . . . . . . . . . . . . . . . . . . . . . . 0

\footnotetext{
* Corresponding author.

E-mail address: capla@soton.ac.uk (C. Ponce de León).
} 


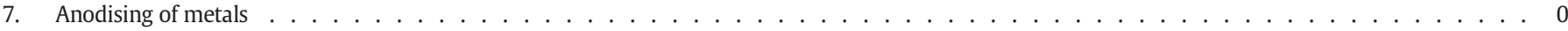

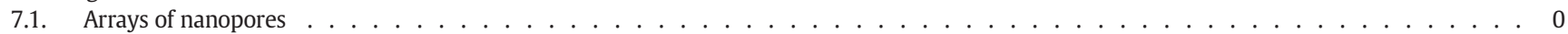

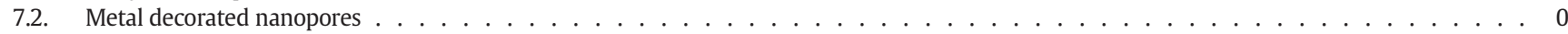

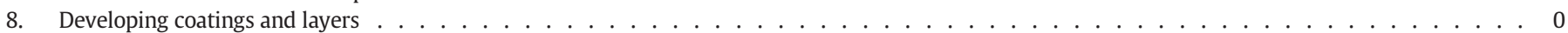

8.1. Nanostructured films . . . . . . . . . . . . . . . . . . . . . . . . . . . . . . 0

8.2. Multi-layered coatings . . . . . . . . . . . . . . . . . . . . . . . . . . . . 0

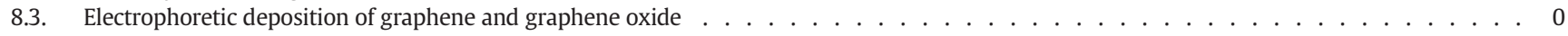

8.4. Hierarchical coatings . . . . . . . . . . . . . . . . . . . . . . . . . . . . . . . . 0

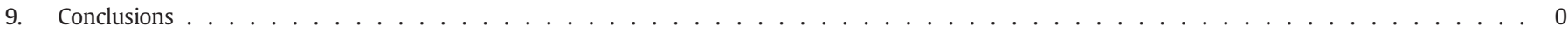

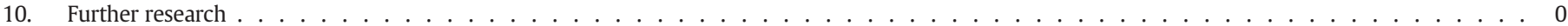

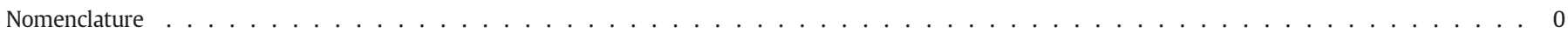

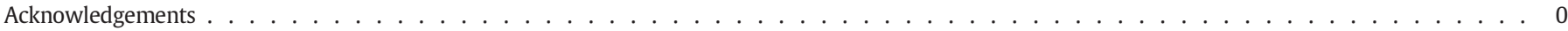

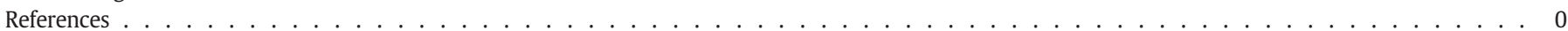

\section{Introduction}

Electrochemical techniques may be used to modify surfaces (e.g. by anodising to produce an oxide film) or cover them with discrete coatings (e.g., by electrodeposition or electrophoresis). The diversity of such layers can be illustrated in several ways. Film thickness varies from several nanometres to tens of micrometres. Both anodic and cathodic films are involved, as are continuous, compact films and nanopore arrays. In terms of surface materials involved, single metals, binary/ternary metal alloys, ceramics and conductive polymers are possible, as are combinations of materials and composite coatings (Fig. 1).

This concise review aims to highlight the benefits of methanesulfonic acid, MSA as an electrolyte for surface finishing, illustrate its ability to produce versatile finishes and coatings then highlight its scope by recent examples from our laboratory. The review considers classical $20 \mu \mathrm{m}$ thick coatings (e.g. for engine bearings) to $50 \mathrm{~nm}$ diameter

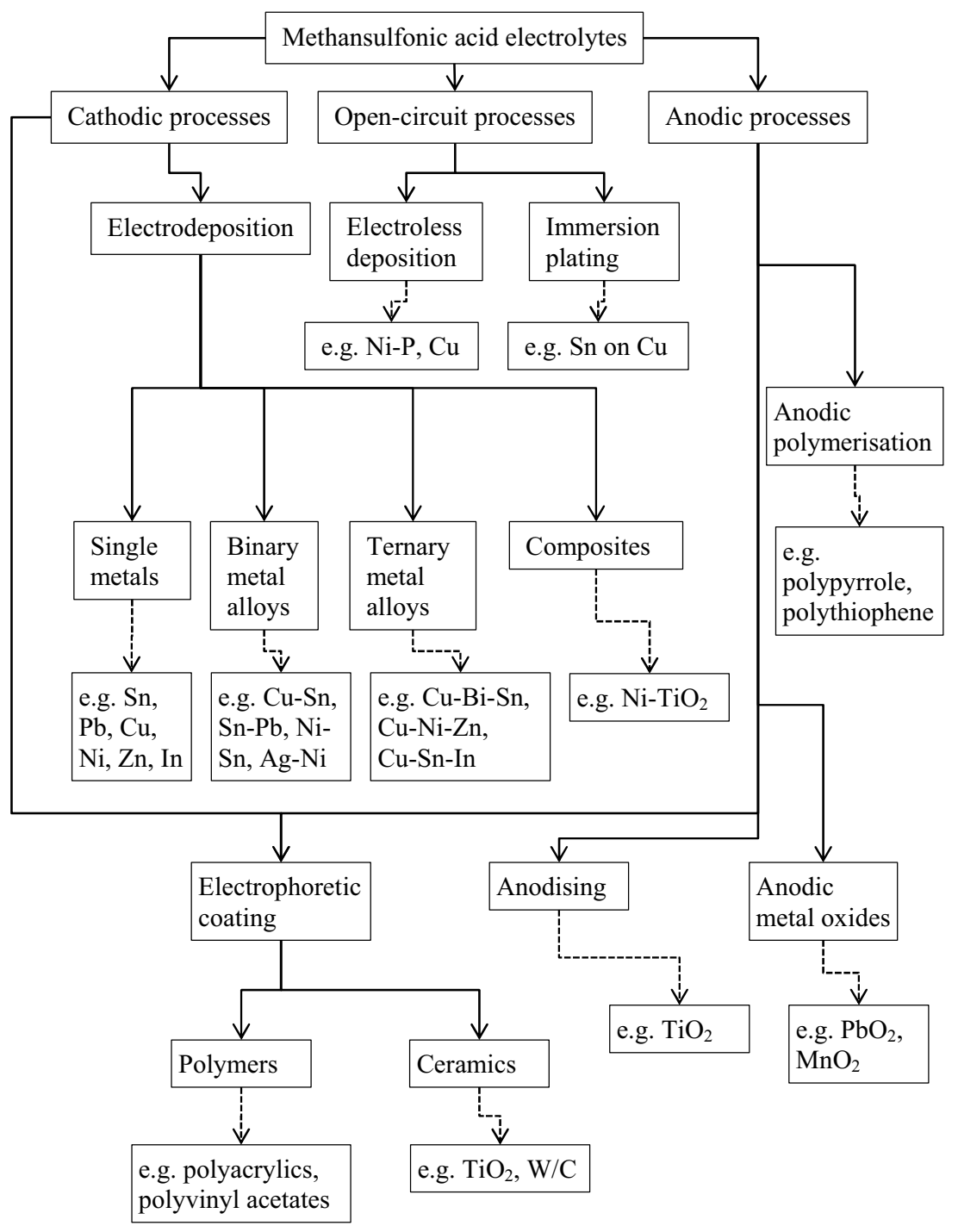

Fig. 1. The diversity of surface coatings and films available from methanesulfonic acid by electrochemical techniques. 
nanotubular arrays in anodised layers which have been over-coated with gold (e.g., for batteries and fuel cells) and several nm thick layers of graphene flakes (electrocatalysis research). Firstly, the general features of MSA are highlighted.

\section{The features of methanesulfonic acid as an electrolyte}

\subsection{General properties}

The general features of this organic acid may be summarised; it:

i. is the simplest alkyl sulfonic acid, $\mathrm{CH}_{3} \mathrm{SO}_{3} \mathrm{H}$, having well-defined chemistry [1]

ii. is normally supplied as a clear, odourless liquid,

iii. is less corrosive than sulphuric acid, at a fixed concentration,

iv. is a non-oxidising acid, with reasonable thermal stability and low vapour pressure,

$\mathrm{v}$. is a strong acid with a comparable ionic conductivity to aqueous hydrochloric acid, and

vi may be considered a 'green' electrolyte since it poses few environmental storage, transport or disposal problems, being readily biodegradeable [2].

MSA was made available commercially for the first time by Guertin in 1964 [3]. This contrasts with fluoroboric acid and fluorosilicic acid, which have been commercially available since the early 1900s. This relatively late arrival of MSA is attributable to the greater difficulty of preparing alkanesulfonic acids on a large scale. Major enhancements in MSA availability are due to the an improved industrial manufacturing process by Pennwalt Corporation in 1964 and, more recently, the bringing on-line of a new manufacturing facility at BASF Chemicals in 2003 [4].

MSA has become the most commonly used and the lowest cost member of a family containing many alkylsulfonic acids such as propanesulfonic acid, butanesulfonic acid and hexanesulfonic acid although many alkylsulfonic acids and their derivatives find specialist uses as reagents in analytical and synthesis chemical laboratories and in industry. Chemically, MSA can be considered as intermediate between sulphuric acid and methylsulfonyl methane $\left(\mathrm{CH}_{3}\right)_{2} \mathrm{SO}_{2}$, a $-\mathrm{CH}_{3}$ group being replaced by $-\mathrm{OH}$ without attack on the $-\mathrm{SO}_{2}$ group. Table 1 provides an overall comparison with sulphuric acid; the latter represents one of the world's major tonnage commodity chemicals and is readily available from multiple sources at a modest price. General applications of MSA include a solvent for organic synthesis, catalyst manufacture and a cleaner for scale removal.

\subsection{Environmental acceptability, synthesis and relative cost}

MSA is supplied as a $70 \mathrm{wt} . \%$ aqueous solution under the brand name Lutropur ${ }^{\circledR}$ MSA [4]. Anhydrous MSA is also available under the brand name Lutropur MSA 100. Both BASF's original production facility in Ludwigshafen, Germany (commissioned in 2003, with an annual capacity of 10,000 metric tons) and the extension (commissioned in 2012, having an annual capacity of 20,000 metric tons) operate a process involving dimethyldisulfide synthesis and oxidation which realises a low sulphate, halogen-free product containing very low levels of contaminant metals. With a total annual manufacturing capacity of 30,000 metric tons, BASF has become the world's leading supplier of MSA. A final distillation step during manufacture helps to realise the low impurity levels that are present in MSA, typically $<1 \mathrm{ppm}$ chlorine, $<20 \mathrm{ppm} \mathrm{SO}_{4}^{2-}$ and $<1 \mathrm{ppm}$ metal ions.

The 'green' character of MSA arises for several reasons. In general, MSA is less toxic than fluoroboric acid and fluorosilicic acid and avoids their lachrymatory properties, both acids being able to evolve acrid fumes of HF. Aqueous MSA solutions do not, under normal conditions, evolve any dangerous volatile chemicals, facilitating their storage, transport and handling in the laboratory and in the industrial process environment.

MSA is considered readily biodegradable, ultimately forming sulphate and carbon dioxide. Indeed, MSA is considered to be a natural product being part of the sulphur cycle. In contrast, discharged fluoroboric acid undergoes hydrolytic dissociation into boric acid and corrosive fluoride ions while discharged fluorosilicic acid undergoes hydrolytic dissociation into silicic acid and fluoride ions. In the case of fluoroboric acid, both fluoride and boron are environmentally troublesome, while for fluorosilicic acid, the fluoride ion is problematic [2]. The benign nature of MSA, especially when compared to fluorinecontaining complex acids, makes it an environmentally acceptable electrolyte.

World prices have been influenced by manufacture of MSA by other countries over the last few years, including PR China. Inevitably, pure, low volume laboratory costs are higher than large-scale volumes. A typical laboratory price is 250 pounds sterling $(\approx 420$ USD) for 251 of $99.5 \%$ purity MSA while prices for $100 \mathrm{l}$ can be $600-1000$ pounds ster$\operatorname{ling}(\approx 1000-1700$ USD).

\subsection{Solubility and electrolytic conductivity}

The general synthesis and chemistry of alkylsulfonic acids are considered, in detail, elsewhere [5]. A useful compilation of fluid properties on various concentrations of aqueous MSA has been provided by Roitman, McAlister and Oaks [6]. The solubility and electrolytic

Table 1

The general features of methanesulfonic acid as an electrolyte and their benefits.

\begin{tabular}{|c|c|}
\hline Feature & Benefit \\
\hline $\begin{array}{l}\text { The simplest and most common of the alkane sulfonic acids; } \mathrm{CH}_{3} \mathrm{SO}_{3} \mathrm{H} \\
M=96.11 \mathrm{~g} \mathrm{~mol}^{-1}\end{array}$ & Well researched and documented \\
\hline Manufactured at a moderate scale (several hundred tonnes per annum) & $\begin{array}{l}\text { Reasonable cost. Good availability of pure solutions at several concentrations in water } \\
\text { (e.g., } 77 \text { wt.\% and } 99 \text { wt.\%) }\end{array}$ \\
\hline Low vapour pressure of $1 \mathrm{~mm} \mathrm{Hg}$ at $20{ }^{\circ} \mathrm{C}$ and a fluid density of 1.481 at $25{ }^{\circ} \mathrm{C}$ & $\begin{array}{l}\text { Low vapour emissions result in low corrosion of neighbouring metals, few storage/transport } \\
\text { problems and ease of pumping. }\end{array}$ \\
\hline Good electrolytic conductivity & Reasonable throwing power and moderate cell voltage in electrolytic coating processes \\
\hline Moderate corrosivity & $\begin{array}{l}\text { Less corrosive than, e.g., sulfuric acid under similar concentration and temperature conditions, } \\
\text { facilitating storage, transport and handling }\end{array}$ \\
\hline Moderately strong acid, with a $p K_{a}=-1.8$ [7] & $\begin{array}{l}\text { Provides cleaning ability for, e.g., metal oxide and scales together with strong acid solution } \\
\text { conditions }\end{array}$ \\
\hline Offers a high solubility of metals & $\begin{array}{l}\text { Ability to prepare high concentration solutions, e.g., metal electroplating baths capable of } \\
\text { operating at high currents hence high coating rates }\end{array}$ \\
\hline Readily biodegradable & Facilitates effluent treatment and disposal of used material; minimises environmental threats \\
\hline $\begin{array}{l}\text { Reasonable thermal stability, with a melting point of } 17-19^{\circ} \mathrm{C} \text { and a boiling } \\
\text { point of } 167{ }^{\circ} \mathrm{C} \text { at } 10 \mathrm{~mm} \mathrm{Hg}\left(122^{\circ} \mathrm{C} \text { at } 1 \mathrm{~mm} \mathrm{Hg}\right)\end{array}$ & Operation over a wide temperature range is possible \\
\hline
\end{tabular}


conductivity of this strong organic acid is particularly important in providing an electrolyte for surface finishing applications.

Some metal salts, including those of $\mathrm{Cu}, \mathrm{Ni}$ and $\mathrm{Sn}$, are soluble in most acid electrolytes, such as $\mathrm{H}_{2} \mathrm{SO}_{4}, \mathrm{HCl}$, and $\mathrm{HBF}_{4}$, and solubility is not important in the selection of acid electrolytes for electroplating processes. Other metal salts, such as those of $\mathrm{Pb}$ and $\mathrm{Ag}$, are only soluble in a limited number of acid electrolytes, and solubility is paramount in the composition and utilisation of acid electrolytes for such metals. The high solubility of the metal salts of MSA makes it an attractive electroplating electrolyte. The solubility advantage is particularly great for $\mathrm{Sn}(\mathrm{II}), \mathrm{Pb}$ (II) and $\mathrm{Ag}$ (I) salts. The saturation solubility of some metal methanesulfonates is shown in Table 2 [3]. The high solubility of $\mathrm{Ag}(\mathrm{I}), \mathrm{Sn}(\mathrm{II})$ and $\mathrm{Pb}(\mathrm{II})$ and salts of MSA relative to the corresponding salts of sulphuric acid is clear. Also, the high solubility of $\mathrm{Ag}(\mathrm{I}), \mathrm{Pb}(\mathrm{II})$ and salts of MSA, relative to the corresponding salts of hydrochloric acid, is clearly seen. The universal aqueous solubility of metal salts of MSA is similar to that of metal salts of nitric acid and (dangerous to store) perchloric acid but MSA offers significant other advantages.

The molar electrolytic conductivity vs. the square root of MSA concentration at $25{ }^{\circ} \mathrm{C}$, compared to common mineral acids, is shown in the Kohlrausch plot of Fig. 2. The higher equivalent conductivity of MSA compared to $\mathrm{H}_{2} \mathrm{SO}_{4}$ over the concentration range of 0.01 to $2 \mathrm{~N}$ is notable.

Fig. 3 indicates the diversity of nanostructured surface coatings and films available from methanesulfonic acid by electrochemical techniques. Anodic and cathodic processes resulting in metals, alloys, polymers, ceramics together with combinations and composites are involved with a layer thickness which can vary from welldefined geometries on a nanometre scale to complex multicomponent, multistructured, millimetre thick coatings. In contrast to many techniques for modification of engineering surfaces, scale is readily varied and often conventional processing facilities, such as anodising and electroplating lines can be deployed.

\section{Electrodeposition of metals}

\subsection{General considerations}

The early use of MSA in the 1970s and 1980s was particularly electroplating of $\mathrm{Sn}$ and $\mathrm{Pb}$ in electronics [7] and $\mathrm{Pb}$ alloys for bearings. Applications in tin alloy, lead-free solder deposits, have followed. In the case of electroplating, Nobel et al. [8] introduced early plating baths

Table 2

The aqueous saturation solubility of some metal methanesulfonates, chlorides and sulphates at $22^{\circ} \mathrm{C}$.

After Gernon et al. [2].

\begin{tabular}{|c|c|c|c|}
\hline \multirow[t]{2}{*}{ Cation } & \multicolumn{3}{|c|}{ Aqueous saturation solubility $/ \mathrm{mol} \mathrm{dm}{ }^{-3}$ as the metal salt } \\
\hline & Methanesulfonate & Sulphate & Chloride \\
\hline $\mathrm{NH}_{4}^{+}$ & 6.83 & 8.17 & 5.06 \\
\hline $\mathrm{Li}^{+}$ & 7.06 & 4.90 & 9.37 \\
\hline $\mathrm{Na}^{+}$ & 5.65 & 2.78 & 5.57 \\
\hline $\mathrm{K}^{+}$ & 4.48 & 1.25 & 3.86 \\
\hline $\mathrm{Mg}^{2+}$ & 1.40 & 2.63 & 5.02 \\
\hline $\mathrm{Ca}^{2+}$ & 2.92 & 0.025 & 5.51 \\
\hline $\mathrm{Ba}^{2+}$ & 1.59 & 0 & 1.71 \\
\hline $\mathrm{Mn}^{2+}$ & 2.90 & 3.52 & 4.12 \\
\hline $\mathrm{Co}^{2+}$ & 2.53 & 2.16 & 3.87 \\
\hline $\mathrm{Ni}^{2+}$ & 2.13 & 2.44 & 4.38 \\
\hline $\mathrm{Cu}^{2+}$ & 2.00 & 1.35 & 4.87 \\
\hline $\mathrm{Ag}^{+}$ & 3.72 & 0.055 & 6.0 \\
\hline $\mathrm{Zn}^{2+}$ & 2.16 & 3.32 & 13.0 \\
\hline $\mathrm{Cd}^{2+}$ & 3.20 & 3.10 & 5.71 \\
\hline $\mathrm{Sn}^{2+}$ & 3.73 & 1.42 & 4.91 \\
\hline $\mathrm{Pb}^{2+}$ & 2.60 & 0 & 0.0338 \\
\hline
\end{tabular}

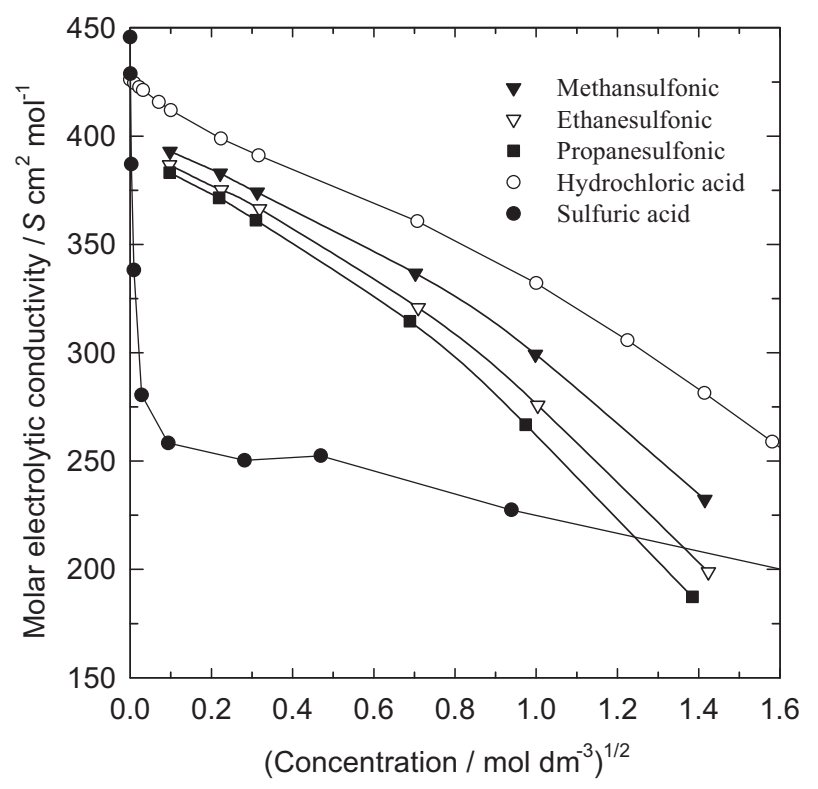

Fig. 2. Molar electrolytic conductivity vs. square root of concentration for aqueous MSA at $25{ }^{\circ} \mathrm{C}$, compared to common mineral acids. After Gernon, Wu, Buszta and Janney [2]. Data for $\mathrm{HCl}$ and $\mathrm{H}_{2} \mathrm{SO}_{4}$ is from CRC Handbook of Chemistry and Physics 95th Ed., 2014-2015.

based on MSA. The last decade has seen MSA become the accepted and often the preferred bath for electroplating tin and tin alloys in electronics and bearings. There has also been a widening of applications for MSA electrolytes in surface finishing as this review attempts to illustrate.

The growing requirements of the electronics industry have forged increased interest in tin, lead and tin-lead electroplating solutions. Such baths are now used to plate components used in numerous engineering, communications, military and consumer product applications, including printed circuit boards, connectors, valves, bearings, semiconductors, transistors, wire leads and connector strip. Tin and tin-lead alloys are solderable and used extensively to bond electronic components.

As noted by Rosenstein [7], MSA (typically as a 10 vol.\% solution) is sometimes used in pre-treatment, prior to electroplating, to remove surface oxides. It is also used to strip metals such as nickel, tin, lead, tin-lead and cadmium from copper and its alloys or from zinc and its alloys prior to re-plating of reclaimed parts.

\subsection{Electroplating of single metals}

Tin was the first common metal to be electroplated from an aqueous MSA bath. Other metals include copper, lead, silver, zinc, nickel and indium.

The electrodeposition of tin from modern electrolytes, including MSA has recently been reviewed $[9,10]$. As an example of tin electrodeposition from a simple, acid electrolyte in the absence of bath additives, studies by Low et al. [11] can be considered. Tin coatings with a matte appearance could be electrodeposited onto copper from methanesulfonic acid at $23{ }^{\circ} \mathrm{C}$. Controlled flow conditions were also examined using a copper rotating disc electrode. The authors note the electrochemical reactions of tin using voltammetric data and consider the diffusion coefficient of stannous ion, nucleation and growth of tin onto copper and the microstructure of tin deposits.

Fig. 4(a) shows the cyclic voltammogram recorded for an additivefree electrolyte containing $0.006 \mathrm{~mol} \mathrm{dm}^{-3} \mathrm{Sn}^{2+}$ in $1.93 \mathrm{~mol} \mathrm{dm}^{-3}$ $\mathrm{CH}_{3} \mathrm{SO}_{3} \mathrm{H}$ at $23^{\circ} \mathrm{C}$. The electrodeposition of tin onto copper started at approximately $-0.444 \mathrm{~V}$ vs. $\mathrm{Ag} \mid \mathrm{AgCl}$. A single cathodic current density 


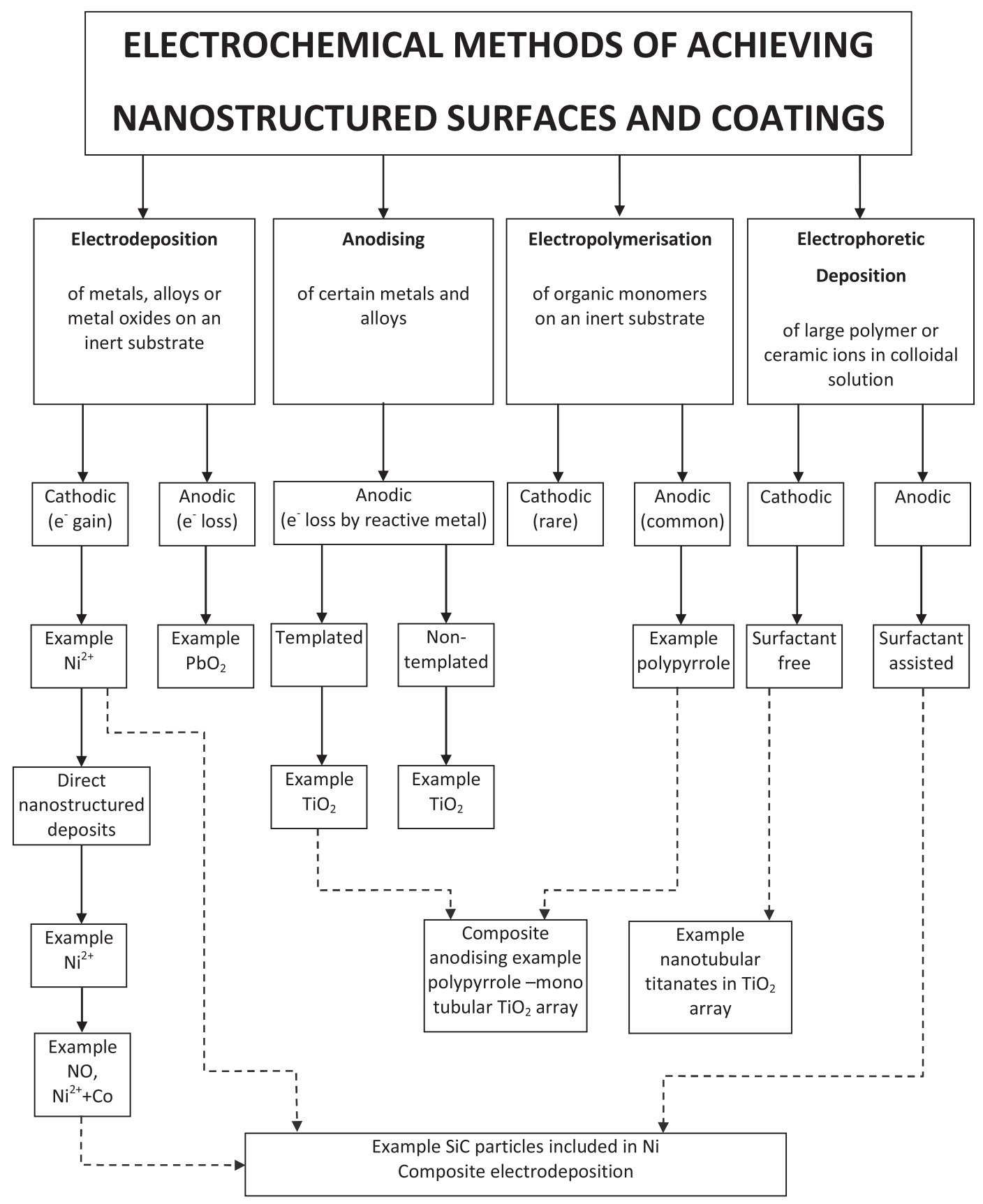

Fig. 3. Approaches to achieving nanostructured coatings and surface finishes.

peak was observed on the forward scan, corresponding to the reduction of $\mathrm{Sn}^{2+}$ to $\mathrm{Sn}$.

$\mathrm{Sn}^{2+}+2 \mathrm{e}^{-} \rightarrow \mathrm{Sn}$

A further rise in the cathodic current density at more negative potentials is due to hydrogen evolution as a secondary reaction:

$2 \mathrm{H}^{+}+2 \mathrm{e}^{-} \rightarrow \mathrm{H}_{2}$

and an increase in the surface area of the deposit. A single anodic peak current density was observed on the reverse scan. The forward and reverse curves indicated that no significant overpotential was required for the deposition of tin onto copper.
On reversing the potential sweep from -0.8 to $0 \mathrm{~V} v$ s. $\mathrm{Ag} / \mathrm{AgCl}$, a single stripping peak (peak B) was observed, confirming the twoelectron oxidation step of metallic tin to stannous ion, i.e. anodic stripping of tin corresponding to the reverse of reaction (1). Voltammetry in the background electrolyte (12.5 vol.\% MSA) shows neither a reduction nor an oxidation peak. The forward and reverse curves show no crossover, i.e. no nucleation loop or overpotential was required as the deposition of tin was thermodynamically favourable at more negative potential on a copper substrate. The efficiency of tin anodically stripped from the copper substrate, $\phi_{\text {strip }}$ can be estimated according to:

$\% \phi_{\text {strip }}=\frac{q_{\text {stripping }}}{q_{\text {deposition }}} \times 100$ 


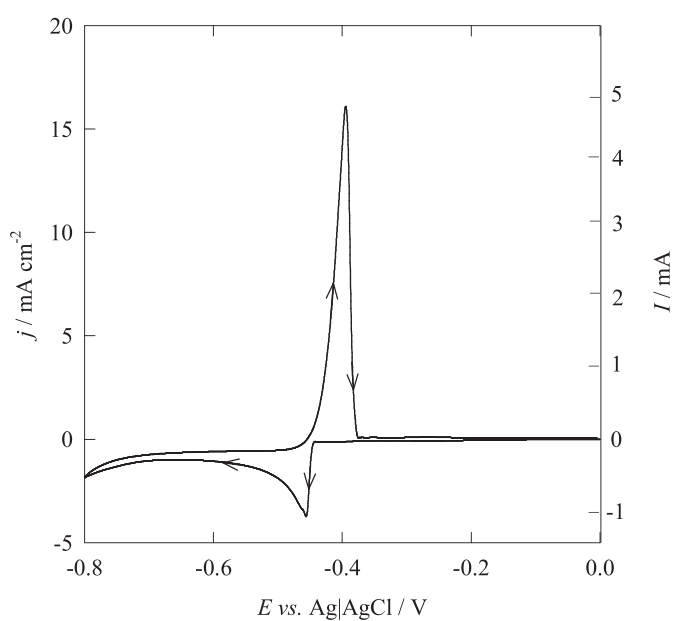

a)

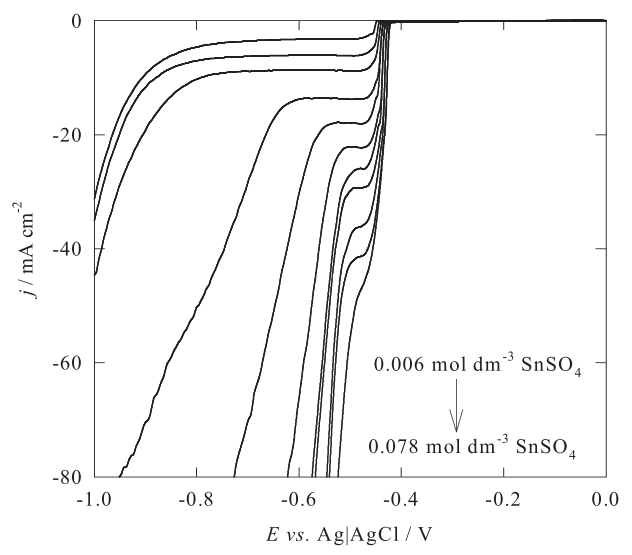

b)

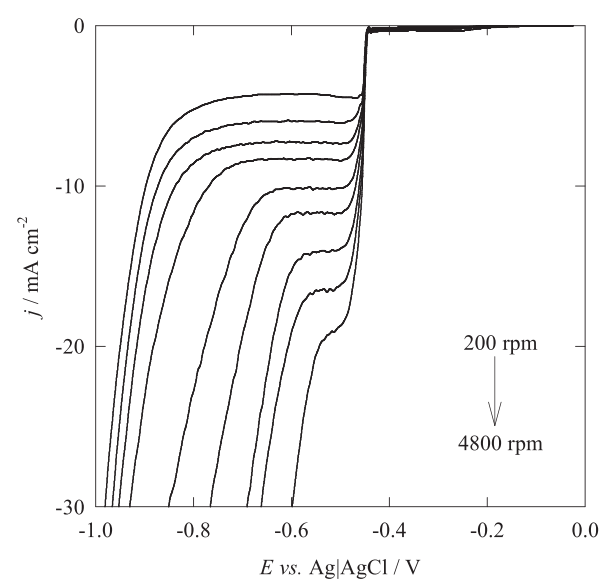

c)

Fig. 4. The voltammetry of $\mathrm{Sn}^{2+} / \mathrm{Sn}$ in an additive-free tin methanesulfonate acid electrolyte. (a) The effect of potential sweep rate on the deposition and stripping of tin, (b) the effect of rotating disc speed (200-4800 rev min ${ }^{-1}$ ) on the deposition of tin and (c) the effect of stannous ion concentration on the deposition of tin. The electrolyte composition was $0.014 \mathrm{~mol} \mathrm{dm}^{-3} \mathrm{SnSO}_{4}$ and 12.5 vol.\% $\mathrm{CH}_{3} \mathrm{SO}_{3} \mathrm{H}$ at $295 \mathrm{~K}$. A static copper disc electrode of $0.28 \mathrm{~cm}^{2}$ area was used and the potential was swept at $16 \mathrm{mV} \mathrm{s}^{-1}$. After Low and Walsh [15].

where $q$ is the charge under the current vs. potential curve. The stripping efficiency was estimated in the range of 50 to $60 \%$ for various potential sweep rates. The low stripping efficiency is attributable to the corrosion behaviour of tin. When tin metal is dissolved to form stannous ion, $\mathrm{Sn}(\mathrm{II})$, immediate oxidation to a more stable and higher state of stannic ion, $\mathrm{Sn}(\mathrm{IV})$ occurs in the presence of dissolved oxygen. It is known that tin will undergo hydrolysis in the acidic medium, where stannic hydroxide can form a passive film on the electrode surface:

$2 \mathrm{Sn}^{2+}+\mathrm{O}_{2}+6 \mathrm{H}_{2} \mathrm{O} \rightarrow 2 \mathrm{Sn}(\mathrm{OH})_{4}+4 \mathrm{H}^{+}$.

The stability of the film increases with dehydration due to oxide formation:

$\mathrm{Sn}(\mathrm{OH})_{4} \rightarrow \mathrm{SnO}_{2} \cdot \mathrm{xH}_{2} \mathrm{O}+(2-\mathrm{x}) \mathrm{H}_{2} \mathrm{O}$.

Fig. 4(b) and (c) shows voltammograms for tin deposition onto copper at a rotating disc electrode in the absence of additives. The deposition of tin occurred fast over a wide range of current densities, as evidenced from the mixed control region where the cathodic current density rose very steeply with respect to the electrode potential. For example, the cathodic current density reached up to $50 \mathrm{~mA} \mathrm{~cm}^{-2}$ in an electrolyte containing $0.078 \mathrm{~mol} \mathrm{dm}^{-3} \mathrm{Sn}^{2+}$ and $1.93 \mathrm{~mol} \mathrm{dm}^{-3} \mathrm{CH}_{3} \mathrm{SO}_{3} \mathrm{H}$. This characteristic is highly attractive for high-speed electroplating of tin where a large current density is used to deposit tin over a short period of time. The cathodic voltammetry also showed a distinctive limiting mass transport plateau which corresponded to the complete reduction of $\mathrm{Sn}^{2+}$ to $\mathrm{Sn}$. The current density was limited by diffusion of stannous ion and increased at a higher electrode rotation speed. Co-evolution of hydrogen was shown to occur at more positive potentials and the mass transport region became shorter at higher rotation speeds and at a higher concentration of stannous ion. These results are similar to those for deposition of tin from a commercial methanesulfonic acid electrolyte [12].

Voltammetry showed that tin was deposited onto copper over a limited linearity Tafel region. Extraction of pure charge transfer data from the mixed control region gave a Tafel slope of approximately $-20 \mathrm{mV}$ decade ${ }^{-1}$. Voltammetry measurements under pure mass transport controlled tin deposition, including rotating disc studies have been used to estimate the diffusion coefficient of $\mathrm{Sn}^{2+}$, typical values in the range $5.2-6.2 \times 10^{-6} \mathrm{~cm}^{2} \mathrm{~s}^{-1}$ being found.

Panels a) to d) of Fig. 5 show the surface microstructure of tin deposited onto copper at constant potential. At an electrode potential from -0.45 to $-0.65 \mathrm{~V}$ vs. $\mathrm{Ag} \mid \mathrm{AgCl}$, a non-dendritic tin deposit having a matte appearance was observed. At more negative potentials from -0.75 to $-0.95 \mathrm{~V}$ vs. $\mathrm{Ag} \mid \mathrm{AgCl}$, the tin deposit was porous due to the co-evolution of hydrogen and needle-like dendrites were observed. At even more negative potentials, the dendrites grew into tree-like branches with length from 100 to $200 \mu \mathrm{m}$.

The results of these electrochemical studies [11] may be summarised as follows:

1. Matte tin coatings were electrodeposited onto copper from additivefree acidic methanesulfonate electrolyte at room temperature $(295 \mathrm{~K})$ at a rotating disc electrode from an electrolyte containing 0.006 to $0.078 \mathrm{~mol} \mathrm{dm}^{-3} \mathrm{Sn}^{2+}$ in $1.93 \mathrm{~mol} \mathrm{dm}^{-3} \mathrm{CH}_{3} \mathrm{SO}_{3} \mathrm{H}$;

2. Electrodeposition of tin onto copper occurred readily over a narrow range of charge transfer and mixed control potential region. A welldefined limiting mass transport controlled region and co-evolution of hydrogen were shown to be dependent on the stannous ion concentration and rotating disc speed;

3. The Levich, Koutécky-Levich and Randles-Sevćik equations below, were used to evaluate the electrodeposition of Sn using different voltammetric data. No significant overpotential was required for tin deposition, indicating a facile process;

Levich

$$
j_{\mathrm{L}}=0.62 n F D^{2 / 3} v^{-1 / 6} c \omega^{0.5}
$$

Koutécky-Levich $\quad-1 / j_{L}=1 / n F k_{c} c_{0}$

$$
+1.61 v^{1 / 6} / n F D^{2 / 3} c_{0} \omega^{0.5}
$$




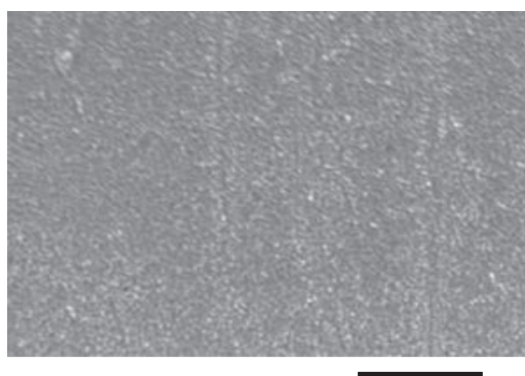

a) $20 \mu \mathrm{m}$
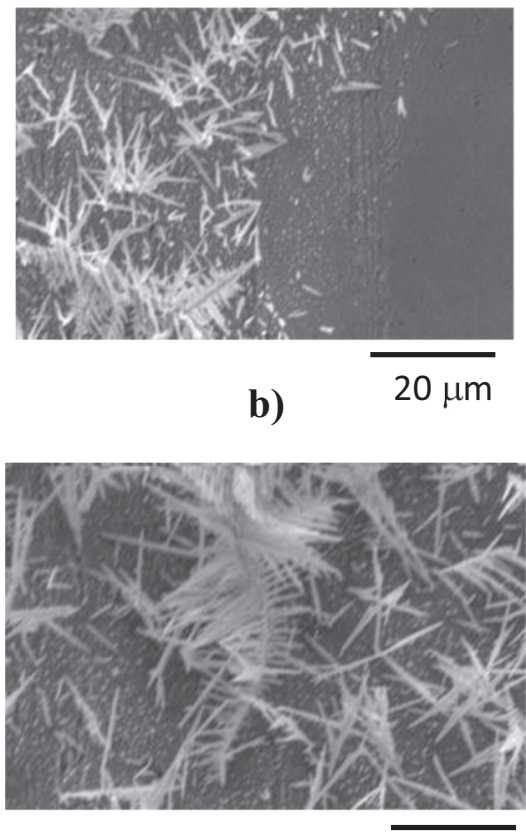

c) $20 \mu \mathrm{m}$

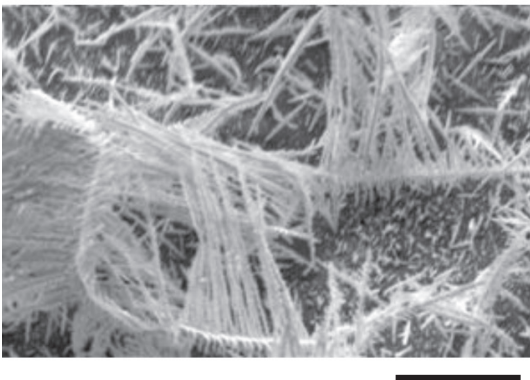

d) $20 \mu \mathrm{m}$

Fig. 5. Scanning electron micrographs showing the surface morphology of tin deposits from a bath containing $0.014 \mathrm{~mol} \mathrm{dm}^{-3} \mathrm{SnSO}_{4}$ and $12.5 \mathrm{vol} . \% \mathrm{CH}_{3} \mathrm{SO}_{3} \mathrm{H}$ at (a) $-0.65 \mathrm{~V}$, (b) $-0.75 \mathrm{~V}$, (c) $-0.85 \mathrm{~V}$ and (d) $-0.95 \mathrm{~V}$ vs. $\mathrm{Ag} \mid \mathrm{AgCl}$

After Low, Kerr, Ponce de Leon and Walsh [11]

Randles-Sevćik $\quad j_{\mathrm{p}}=\left(2.69 \times 10^{5}\right) n^{1.5} D^{0.5} \mathrm{cv}$.

4. The tin deposits were compact, non-dendritic and adherent to the copper substrate; early deposition occurred via an instantaneous three-dimensional nucleation growth mechanism. Needle-like dendrites were obtained at potentials where co-evolution of hydrogen occurred.
5. Current transients indicated that tin deposition on copper closely matched an instantaneous 3-D nucleation-growth model.

6. In the electrode potential range from -0.45 to $-0.65 \mathrm{~V} \mathrm{vs}$. $\mathrm{Ag} \mid \mathrm{AgCl}, \mathrm{a}$ non-dendritic tin deposit having a matte appearance was observed. From -0.75 to $-0.95 \mathrm{~V}$ vs. $\mathrm{Ag} \mid \mathrm{AgCl}$, the tin deposit was porous due to the co-evolution of hydrogen and needle-like dendrites. At even more negative potentials, the dendrites grew into tree-like branches with length from 100 to $200 \mu \mathrm{m}$.

Studies in the authors' laboratory resulted in a series of publications on the voltammetry of tin deposition and the deposit morphology from methanesulfonic acid solutions in more detail. The first paper considered a mixed sulphate-methanesulfonate acid electrolyte [13]. The deposition of tin onto copper and the stripping of tin from an electrolyte containing $0.014 \mathrm{~mol} \mathrm{dm}^{-3} \mathrm{SnSO}_{4}$ in $12.5 \mathrm{vol}$.\% MSA at $295 \mathrm{~K}$ was studied using cyclic voltammetry at a static disc and linear sweep voltammetry at a rotating disc electrode. Overall, the electrode kinetics proved similar to those in pure acid methanesulfonate baths. The diffusion coefficient of stannous ion was found to be $6.5 \pm 0.6 \times 10^{-6} \mathrm{~cm}^{2} \mathrm{~s}^{-1}$ using linear sweep voltammetry at an RDE.

A second paper [14] focused on the importance of a hydroquinone antioxidant in baths containing $0.014 \mathrm{~mol} \mathrm{dm}^{-3} \mathrm{SnSO}_{4}$ and 12.5 vol.\% methanesulfonic acid ( $\left.1.93 \mathrm{~mol} \mathrm{dm}^{-3} \mathrm{MSA}\right)$ at $296 \mathrm{~K}$. The Levich and Randles-Sevčik equations were used to evaluate the mass transport characteristics of stannous ions at various potential sweep rates, electrode rotation speeds and hydroquinone concentrations. The diffusion coefficient of stannous ions was found to be $7.7 \pm 0.5 \times 10^{-6} \mathrm{~cm}^{2} \mathrm{~s}^{-1}$. Tin was electrodeposited onto a copper surface over a narrow potential range under charge transfer and mixed control with a well-defined mass transport control region. Voltammetry showed a negligible charge transfer overpotential. At a stationary electrode, a single reduction and oxidation peak were observed in the absence and presence of hydroquinone. At a rotating disc electrode, a single limiting plateau was seen, corresponding to the two electron transfer of stannous ions to metallic tin. The region of complete mass transport control and the onset of hydrogen evolution were dependent on the electrode rotation speed and hydroquinone concentration. When the concentration ratio of hydroquinone to stannous ion was 0.36 and 3.6, the complete mass transport control region was lengthened and the hydrogen evolution was shifted to more electronegative potentials. Electrolyte stability was monitored with storage time via changes in the deposition charge and stripping efficiency together with the peak and limiting current densities. In the absence of hydroquinone, a significant loss in these variables is observed. The addition of hydroquinone to the electrolyte served to significantly reduce the rate of stannous ion oxidation to stannic ion. The electrolyte stability against storage hours was monitored via changes in the deposition charge and stripping efficiency. Tin was electrodeposited at $-0.5 \mathrm{~V}$ vs. $\mathrm{Ag} / \mathrm{AgCl}$ for $30 \mathrm{~s}$ and then stripped from $-0.5 \mathrm{~V}$ to $0 \mathrm{~V}$ vs. $\mathrm{Ag} / \mathrm{AgCl}$. In the $\mathrm{ab}-$ sence of hydroquinone, only $37 \%$ of the original deposition charge was maintained after $512 \mathrm{~h}$. When hydroquinone was present, the deposition charge remained closely similar for the duration of studies. The addition of hydroquinone as an antioxidant is clearly realised in minimising the oxidative rate of stannous to stannic ions. At a relatively saturated hydroquinone concentration $\left(0.5 \mathrm{~mol} \mathrm{dm}^{-3}\right)$, the deposition charge was lower compared with the 0.005 and $0.05 \mathrm{~mol} \mathrm{dm}^{-3}$ hydroquinone. In the absence of the hydroquinone antioxidant, the stripping efficiency decreased with storage time. With hydroquinone in the electrolyte, it remained constant at approximately $83 \%$ with storage time.

The loss in the deposition charge and stripping efficiency was also investigated for tin deposits obtained via cyclic voltammetry. The stripping efficiency decreased with storage time but increased to a steady state at increasing sweep rate. At a lower sweep rate, thicker tin deposits were formed which may improve its adherence and thus lowered the intensity of the stripping efficiency. The stripping efficiency dropped 
from $79 \%$ to $73 \%$ after $512 \mathrm{~h}$, while the stripping efficiency dropped from $53 \%$ to $35 \%$ after $512 \mathrm{~h}$.

A third paper [15] looked in detail at the effect of a perfluorinated cationic surfactant, DuPont ForaFac ${ }^{\circledR} 1098$ in an electrolyte containing $0.014 \mathrm{~mol} \mathrm{dm}^{-3} \mathrm{SnSO}_{4}, 0.005 \mathrm{~mol} \mathrm{dm}^{-3}$ hydroquinone and 12.5 vol.\% (1.93 mol dm${ }^{-3}$ ) methanesulfonic acid at $296 \mathrm{~K}$, plus 12 to $2.4 \mathrm{vol} . \%$ of the surfactant. The effects of this additive on tin plating [15] on voltammetry and morphology can be summarised as follows:

1. Levich and Randles-Sevčik equations were used to evaluate the mass transport characteristics of stannous ions at various potential sweep rates, electrode rotation speeds and surfactant concentrations. Changes in the peak current density (with a static electrolyte) and limiting current density (at controlled RDE speeds) revealed a linear relationship between peak current density and the square root of potential sweep rate in the absence of surfactant but a non-linear relationship when surfactant was added to the electrolyte.

2. Electrodeposition of tin onto a copper surface started at about $-0.445 \mathrm{~V}$ vs. $\mathrm{Ag} \mid \mathrm{AgCl}$ with or without surfactant in the electrolyte, at stationary and control flow conditions. In the absence of surfactant, no overpotential was required for the deposition of tin when a copper substrate was used. In the presence of surfactant, the nucleation of cathodic current density, however, was dependent on the end potential and the presence of adequate solution agitation, an overpotential of approximately $100 \mathrm{mV}$ being required.

3. The role of the surfactant during tin deposition was potential and flow-dependent, from an analysis of surface coverage from the voltammetry. The adsorption orientation of surfactant onto the electrode surface could be altered with possible desorption occurring at more electronegative potential. Its presence hindered hydrogen evolution and accounted for the reduction in peak and limiting current density as well as the lower charge passed from the cyclic voltammetry and potentiostatic control of deposition.

The effects of organic additives on the electrochemical and morphological deposit changes from acid tin methanesulfonate solutions have been considered by Martyak and Seefeldt [16]. In the absence of additives, tin deposition was diffusion-controlled, with concurrent hydrogen gas evolution and the tin deposits were rough. Addition of polyethylene glycol suppressed hydrogen gas evolution yet had little effect on the mechanism of stannous reduction and the deposit structures. Polypropylene glycol enhances stannous ion reduction and produced a smoother tin coating. The addition of phenolphthalein to solutions already containing the glycol additives resulted in a kinetically-controlled tin reduction process and a smooth matte tin deposit.

The electrotinning of steel using MSA baths has gained acceptance in continuous steel strip plating after years of use in the electronics industry. In the reel-to-reel plating of electronics components, the line speed is about $0.1 \mathrm{~m} \mathrm{~s}^{-1}$, the current density is about $20 \mathrm{~A} \mathrm{dm}^{-2}$ and the stannous ion concentration is in the range of 0.420 to $0.840 \mathrm{~mol} \mathrm{dm}^{-3}$ (50 to $100 \mathrm{~g} \mathrm{dm}^{-3}$ ). In contrast, in a continuous steel strip plating line, the steel strip typically travels at speeds from 2 to $10 \mathrm{~m} \mathrm{~s}^{-1}$ while the current density varies from 10 to $65 \mathrm{~A} \mathrm{dm}^{-2}$ to accommodate the mix of various steel grades and coating weights involved. The stannous ion concentration is much lower in strip plating often in the range of 0.084 to $0.168 \mathrm{~mol} \mathrm{dm}^{-3}$ to minimise the loss of costly chemicals through leaks and drag-out in a continuous steel strip plating line. A recent study [12] using a proprietary MSA bath, Ronastan-TP-HCD (Shipley Ronal) has examined how the deposition process is affected by the hydrodynamic conditions created by the fast moving strip, such an understanding being critical for process control.
The electrodeposition of rare metals from MSA has included indium and gallium for semiconductor electronics. For example, a patent has described deposition of gallium, Ga-In and their alloys with copper [17].

The deposition of copper from an MSA bath in the presence of a fluorocarbon surfactant (DuPont's Forafac 1098) has been studied by Low and Walsh [18]. The baths contained 0.02 to $0.5 \mathrm{~mol} \mathrm{dm}^{-3}$ copper, $0.005 \mathrm{~mol} \mathrm{dm}^{-3}$ hydroquinone and $12.5 \mathrm{vol} . \%\left(1.93 \mathrm{~mol} \mathrm{dm}^{-3}\right) \mathrm{MSA}$ and 0.002 to 0.12 vol.\% surfactant at $23{ }^{\circ} \mathrm{C}$. The effects of rotating disc electrode rotation speed, surfactant concentration and copper ion concentration were investigated. Linear sweep voltammetry was used to identify the charge transfer, mixed control and mass transport control regions. Changes in the limiting current density, copper nucleation potential and hydrogen evolution potential were discussed. The shift in copper nucleation potential was also investigated as a function of the surfactant and copper ion concentrations. Copper was electrodeposited, at a constant potential, onto a rotating cylinder electrode and the smooth surface morphology was characterised by scanning electron microscopy.

Silver has been deposited from MSA to avoid the environmental and safety objections to classical cyanide baths [19]. High quality electronic conductors and antique restoration are two of the main applications.

MSA baths have been patented [20] as a replacement for high speed acid nickel sulfamate baths. Such electrolytes are used to produce low internal stress deposits for reclamation of surfaces in heavy engineering by plating thick nickel coatings on steel substrates, followed by machining and polishing.

Nickel electrodeposition from an MSA based bath has been discussed in a US patent [21]. The bath contained $100-400 \mathrm{~g} \mathrm{dm}^{-3} \mathrm{Ni}\left(\mathrm{CH}_{3} \mathrm{SO}_{3}\right)_{2}$, $17-40 \mathrm{~g} \mathrm{dm}^{-3}, \mathrm{H}_{3} \mathrm{BO}_{3}, 0.1-1.8 \mathrm{~g} \mathrm{dm}^{-3}$ saccharin and $0.02-0.5 \mathrm{~g} \mathrm{dm}^{-3}$ sodium lauryl sulphate at $\mathrm{pH} 0.8-2.0$ was operated at $30-60{ }^{\circ} \mathrm{C}$, and $0.5-30 \mathrm{~A} \mathrm{dm}^{-2}$. Compared with known nickel plating baths, such as the Watts bath, the methanesulfonate bath can be considered to have a higher current density and throwing power, higher maximum nickel deposition rates, with deposits having low porosity, low internal stress and high ductility. Good quality deposits without agitation were claimed at $<15 \mathrm{~A} \mathrm{~m}^{-2}$.

MSA and other sulfonic acids have also seen use as bath additives for nickel plating from acid solution. For example, the influence of MSA, naphthalenesulfonic acid and phenolsulfonic acid on the electrodeposition of nickel from a citrate buffered bath has been investigated in research by Sekar and Jayakrishnan [22]. Bath characteristics such as cathode efficiency and throwing power were assessed and the corrosion resistance of the coatings was measured by electrochemical impedance spectroscopy. The X-ray diffraction pattern obtained for the nickel deposit showed a polycrystalline, face centred cubic structure. A uniform and pinhole free surface was observed under SEM analysis.

Zinc deposition and dissolution are important processes in redox flow batteries for load levelling and energy storage [23], including the $\mathrm{Zn}$-air, $\mathrm{Zn}-\mathrm{Br}_{2}$ and $\mathrm{Zn}-\mathrm{Ce}$ cells [24]. In MSA media, used in $\mathrm{Zn}-\mathrm{Ce}$ cells, the reactions at the negative electrode of the battery are as follows:

$$
\mathrm{Zn}^{2+}+2 e^{-} \underset{\text { dis charge }}{\stackrel{\text { charge }}{\rightleftarrows}} \mathrm{Zn} \text {. }
$$

Leung et al. [25,26] and Berlouis et al. [27,28] have considered zinc deposition and dissolution in MSA as the negative electrode reaction in $\mathrm{Zn}-\mathrm{Ce}$ cells.

\subsection{Electroplating of binary metal alloys}

In addition to the well-known $\mathrm{Sn}-\mathrm{Cu}$ (bronze) alloys, examples of alloys electroplated from MSA include $\mathrm{Sn}-\mathrm{Pb}, \mathrm{Sn}-\mathrm{Ni}, \mathrm{Sn}-\mathrm{Bi}$ and $\mathrm{Sn}-$ $\mathrm{Ag}$, the majority of applications being electronic components and interconnects. 
For interconnects in electronics, tin-lead deposits must possess several key characteristics:

1. good solderability and the ability to be thermally annealed and reflowed,

2. low porosity,

3. good corrosion resistance,

4. uniformity of alloy composition and

5. adequate thickness, smoothness and appearance over a wide current density range.

A classical problem with long-term use of tin deposits is whisker formation, particularly when local microstructural stresses are high. Alloy formation is one method used to avoid the effect and has been studied in $\mathrm{Pb}-\mathrm{Sn}$ and $\mathrm{Cu}-\mathrm{Sn}$ deposits from MSA baths in USA research [29].

Since the 1980s, there has been a progressive shift towards lead-free solders due to environmental and health concerns reflected in increasing legislation and more stringent material specifications. Electrodeposition

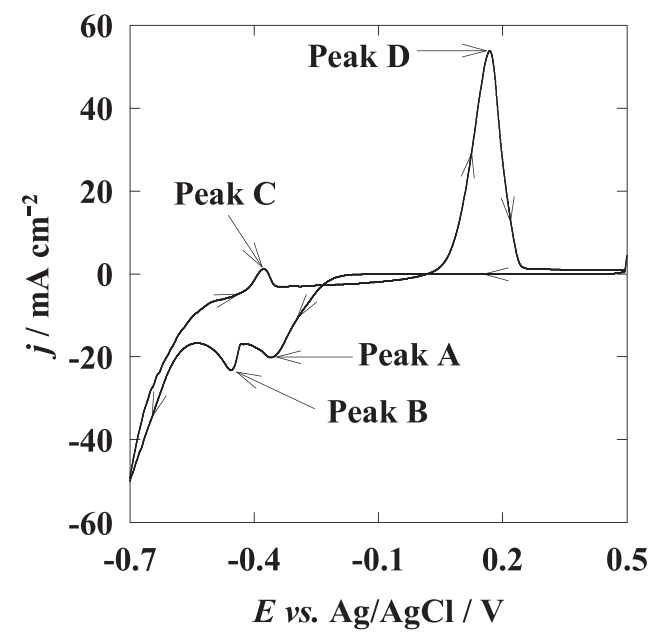

a)

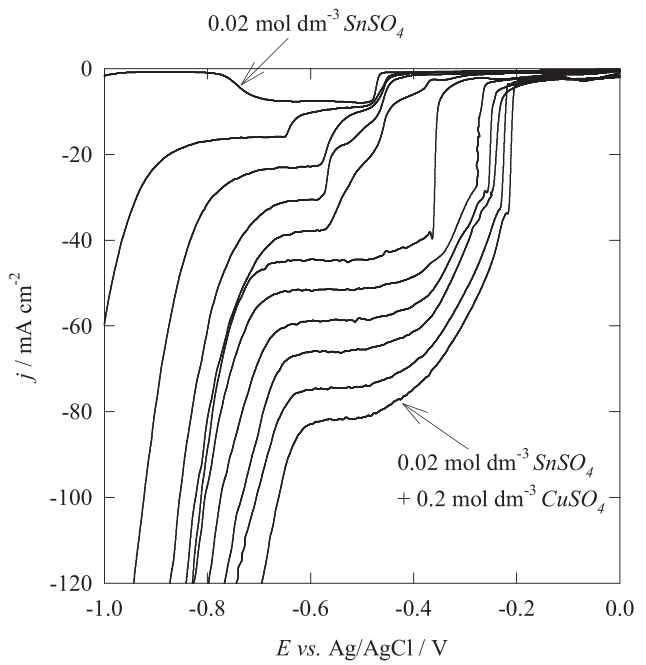

b)

Fig. 6. The voltammetry of MSA baths containing tin and copper. a) Cyclic voltammetry at a stainless steel $\mathrm{RDE}$ ( $3 \mathrm{~cm}$ radius) following a potential sweep from 0.5 to- $0.7 \mathrm{~V} \mathrm{vs.} \mathrm{Ag}$ $\mathrm{AgCl}$ then back to $-0.7 \mathrm{~V}$ vs. $\mathrm{Ag} \mid \mathrm{AgCl}$ in a tin-copper bath. b) Linear sweep voltammetry showing the effect of copper ion concentration on tin-copper alloy deposition at a platinum RDE rotated at $1000 \mathrm{rpm}$ using a potential sweep rate of $16 \mathrm{mV} \mathrm{s}^{-1}$. Each curve represents an increment of $0.02 \mathrm{~mol} \mathrm{dm}^{-3}$ copper ions in bath containing $12.5 \mathrm{vol} \% \mathrm{MSA}$, 0.008 vol.\% surfactant and $0.005 \mathrm{~mol} \mathrm{dm}^{-3}$ hydroquinone. After Low and Walsh [31]. of lead-free tin alloys has become commonplace. Since 2000, MSA baths have been widely used for electroplating of bearing alloys. For example, lead-free $\mathrm{Sn}-\mathrm{Cu}$ and $\mathrm{Sn}-\mathrm{Cu}$-Bi layers are described in a US patent by Tsuji et al. [30]. Other examples of $\mathrm{Sn}-\mathrm{Cu}$ alloys electrodeposited from MSA are available [31-34], as are studies of Bi-Sn [35,36] and Sn-In [37].

Since $\mathrm{Sn-Cu}$ alloy deposits are industrially important in electronics and engineering, these have been recently considered from MSA baths in some detail. Research at Southampton University [31] has examined electrochemical, deposit composition and morphology aspects during electrodeposition of tin-copper alloys from a methanesulfonic acid bath containing hydroquinone antioxidant and a fully fluorinated cationic surfactant. The bath contained 12.5 vol.\% (1.93 $\left.\mathrm{mol} \mathrm{dm}^{-3}\right)$ methanesulfonic acid and a fully fluorinated cationic surfactant, DuPont ForaFac ${ }^{\circledR} 1098$ at 296 K. Electrodeposition was performed under well controlled laboratory flow conditions, using a rotating disc electrode $(\mathrm{RDE})$ in laminar flow and a rotating cylinder electrode (RCE) in turbulent conditions. The electrode rotation speed, deposition potential, copper and tin ion concentrations were investigated. The addition of surfactant was shown to have shifted the copper deposition potential to more negative potential. Golden yellow bronze deposits, containing 70-80 wt.\% copper and 20-30 wt.\% tin were obtained.

Fig. 6a) shows a cyclic voltammogram at a 316L stainless steel disc electrode ( $3 \mathrm{~cm}$ radius, $0.28 \mathrm{~cm}^{2}$ surface area) in bath containing $0.1 \mathrm{~mol} \mathrm{dm}^{-3} \mathrm{CuSO}_{4}, 0.05 \mathrm{~mol} \mathrm{dm}^{-3} \mathrm{SnSO}_{4}, 0.01 \mathrm{~mol} \mathrm{dm}^{-3} \mathrm{MSA}$, $0.01 \mathrm{~mol} \mathrm{dm}^{-3}$ hydroquinone, $\mathrm{C}_{6} \mathrm{H}_{4}(\mathrm{OH})_{2}$ and 0.01 vol.\% DuPont ForaFac ${ }^{\circledR} 1098$ surfactant. The forward swept from $+0.5 \mathrm{~V}$ to $-0.7 \mathrm{~V}$ vs. $\mathrm{Ag} \mid \mathrm{AgCl}$ shows two peaks; Peak $\mathrm{A}$ is the reduction of $\mathrm{Cu}(\mathrm{II})$ to $\mathrm{Cu}(0)$ and the well separated Peak B is the reduction of $\mathrm{Sn}$ (II) to $\mathrm{Sn}(0)$. The reverse sweep from $-0.7 \mathrm{~V}$ to $+0.5 \mathrm{~V}$ vs. $\mathrm{Ag} \mid \mathrm{AgCl}$ shows two peaks: Peak C is the oxidation of Sn (0) to Sn(II) and Peak D represents the oxidation of the copper deposit to $\mathrm{Cu}^{2+}$ ions in solution.

Fig. 6b) shows the effect of copper ion concentration on the linear sweep voltammetry of tin-copper alloy deposition at a platinum RDE at $1000 \mathrm{rpm}$ at a potential sweep rate of $16 \mathrm{mV} \mathrm{s}^{-1}$. Each curve represents an increment of $0.02 \mathrm{~mol} \mathrm{dm}^{-3}$ copper ions in the bath. The electrolyte contained $12.5 \mathrm{vol} . \%$ MSA, 0.008 vol.\% of surfactant and $0.005 \mathrm{~mol} \mathrm{dm}^{-3}$ hydroquinone. The first curve shows tin deposition from $0.02 \mathrm{~mol} \mathrm{dm}^{-3} \mathrm{SnSO}_{4}$ only, and the subsequent curves are tincopper alloy deposition, where $0.02 \mathrm{~mol} \mathrm{dm}^{-3} \mathrm{CuSO}_{4}$ was added to the bath at each increment. The electrolyte has 12.5 vol.\% MSA, 0.008 vol.\% surfactant and $0.005 \mathrm{~mol} \mathrm{dm}^{-3}$ hydroquinone. It was observed that a single limiting plateau was obtained at $0.1 \mathrm{~mol} \mathrm{dm}^{-3}$ $\mathrm{CuSO}_{4}$ and beyond. Below this copper ion concentration in the bath, two or multiple plateaus were seen. The deposition potential for tincopper alloys was also observed to have shifted to more positive potential with increasing copper ion concentrations.

A series of tin-copper alloys has been deposited over a wide range of operating conditions using controlled flow at rotating disc electrode (RDE) and rotating cylinder electrode (RCE) surfaces during research in the author's laboratory [32,33]. Normal (copper deposited at more positive potential than tin) and abnormal tin-copper alloy deposition (tin deposited at more positive potential than copper) can be formulated depending on the copper(II) and surfactant concentration in the baths. For normal alloy deposition, Fig. 7a) shows the surface composition of tin-copper alloys deposited onto the cathode of the rotating cylinder Hull cell (10 minute deposition, RCE at $1000 \mathrm{rpm}$ ). The copper limiting current density at approximately $53 \mathrm{~mA} \mathrm{~cm}^{-2}$ was used as a guideline for the applied current used in the rotating cylinder Hull cell. The applied currents were $120 \mathrm{~mA}, 240 \mathrm{~mA}$ and $320 \mathrm{~mA}$; corresponding to $20 \%, 30 \%$ and $40 \%$ of the limiting current density for copper deposition.

The electrolyte contained $0.1 \mathrm{~mol} \mathrm{dm}^{-3} \mathrm{CuSO}_{4}, 0.06 \mathrm{~mol} \mathrm{dm}^{-3}$ $\mathrm{SnSO}_{4}, 12.5$ vol.\% MSA, $0.005 \mathrm{~mol} \mathrm{dm}{ }^{-3}$ hydroquinone and 0.01 vol.\% surfactant. During tin-copper alloy electrodeposition, the measured cell potential was $2.3,2.7$ and 2.9 respectively. The position at $x=$ 


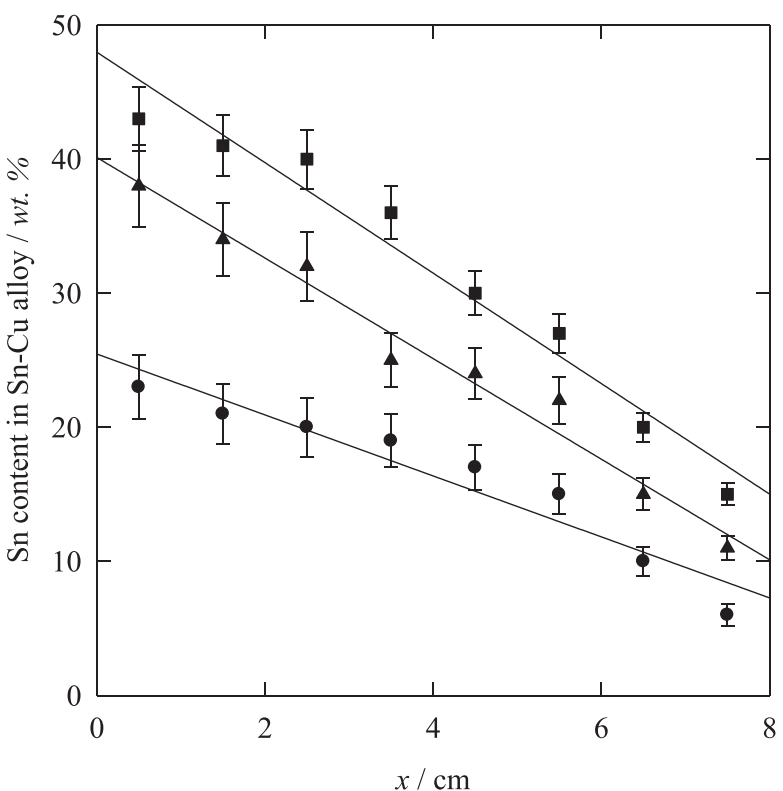

a)

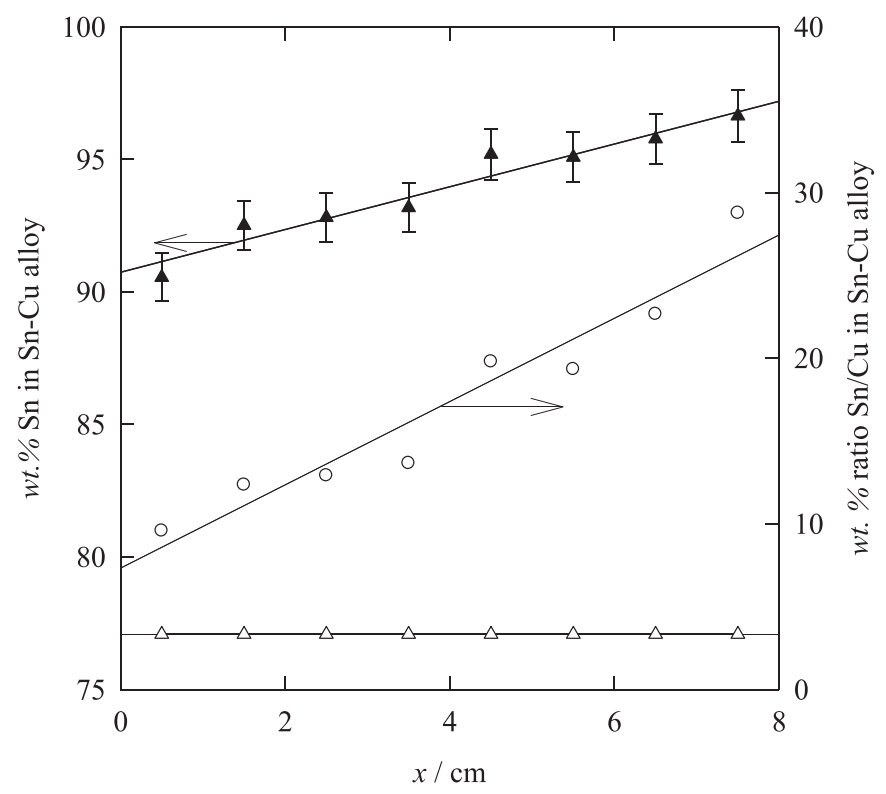

b)

Fig. 7. Surface composition analysis of tin-copper alloy deposits on the cathode of a rotating cylinder Hull cell after 10 minute deposition. (a) Normal alloy deposition. Applied current: $120 \mathrm{~mA} ; \quad 240 \mathrm{~mA}$ and $\boldsymbol{\Delta} 320 \mathrm{~mA}$. The electrolyte contained $0.1 \mathrm{~mol} \mathrm{dm}^{-3}$ $\mathrm{CuSO}_{4}, 0.03 \mathrm{~mol} \mathrm{dm}^{-3} \mathrm{SnSO}_{4}, 12.5$ vol.\% MSA $0.005 \mathrm{~mol} \mathrm{dm}^{-3}$ hydroquinone and 0.01 vol.\% surfactant. (b) Abnormal alloy deposition. Applied current: $200 \mathrm{~mA}$. The electrolyte contained $0.02 \mathrm{~mol} \mathrm{dm}^{-3} \mathrm{CuSO}_{4}, 0.05 \mathrm{~mol} \mathrm{dm}^{-3} \mathrm{SnSO}_{4}, 12.5$ vol.\% MSA, $0.005 \mathrm{~mol} \mathrm{dm}^{-3}$ hydroquinone and $0.01 \mathrm{vol} \%$ surfactant. $\triangle$ wt.\% Sn in the electrolyte and $\mathrm{Sn} / \mathrm{Cu}$ wt. \% ratio in the tin-copper electrolyte. $x=0 \mathrm{~cm}$ is closest to the anode and $x=8 \mathrm{~cm}$ is furthest from the anode. RCE $(0.3 \mathrm{~cm}$ radius, $8 \mathrm{~cm}$ length) was rotated at $1000 \mathrm{rpm}$.

After Low and Walsh [31,32].

$0 \mathrm{~cm}$ is closest to the counter electrode and $x=8 \mathrm{~cm}$ is furthest away from the counter electrode. At low current density, the alloys contained predominantly copper; and $20 \mathrm{wt} . \%$ to $35 \mathrm{wt} . \%$ tin showed a golden yellow surface finishes; and $35 \mathrm{wt} . \%$ to $50 \mathrm{wt} . \%$ tin has a light to dark brown appearance. The RCH cell has allowed to deposit a controlled non-uniform distribution of tin-copper alloys along the cathode length.

Fig. 7b) shows the surface composition of tin preferentially deposited at a more positive potential than copper. The electrolyte contained
$0.02 \mathrm{~mol} \mathrm{dm}^{-3} \mathrm{CuSO}_{4}, 0.05 \mathrm{~mol} \mathrm{dm}^{-3} \mathrm{SnSO}_{4}, 12.5$ vol.\% MSA, $0.005 \mathrm{~mol} \mathrm{dm}^{-3}$ hydroquinone and 0.01 vol.\% surfactant. The copper content increased from 3 to $9 \mathrm{wt}$.\% with the current density increased along the cathode of the rotating cylinder Hull cell [31]. At the lower current density end, e.g. at $x=7.5 \mathrm{~cm}$ the alloy contained $97 \mathrm{wt} . \% \mathrm{Sn}$; and at the higher current density end, e.g. at $x=1.5 \mathrm{~cm}$ the alloy contained $91 \mathrm{wt} . \% \mathrm{Sn}$. A base line comparison between the tin in the alloy and in the bath is also given. It is demonstrated that a low copper content in the alloy can be obtained from a high tin/copper ratio in the bath.

Fig. 8 shows the surface microstructure for electrodeposited $\mathrm{Cu}-\mathrm{Sn}$ alloys of (a) 100 wt.\% tin, (b) 100 wt.\% copper, (c) 35 wt.\% tin-65 wt.\% copper from a normal alloy deposition bath and (d) 96 wt.\% tin4 wt.\% copper from an abnormal alloy deposition bath. The visual appearance of the surface was as follows: (a) matte-grey for tin, (b) reddish orange for copper, (c) bright golden-yellow for the 35 wt.\% tin-65 wt.\% copper alloy and (d) dark grey for the 96 wt.\% tin-4 wt.\% copper alloy. The surface microstructure of tin was orderly packed and pellet-like and the surface finishes were silvery mattwhite colour [32]. Nodules were seen on the surface of copper deposits with a reddish orange surface finishes. The surface microstructure for tin-copper alloys is compact and uniform. Bright golden-yellow colour was observed for $35 \mathrm{wt}$ \% tin-65 wt.\% copper alloy and a dark grey coating was obtained in the case of the $96 \mathrm{wt} . \%$ tin- $4 \mathrm{wt}$.\% copper alloy. The structural phase composition was as follows: (a) $100 \mathrm{wt} . \%$ tin is tetragonal, (b) $100 \mathrm{wt} . \%$ copper is cubic, (c) $35 \mathrm{wt} . \%$ tin-65 wt.\% copper is orthorhombic CuSn and (d) $96 \mathrm{wt} . \%$ tin-4 wt.\% copper containing two phases: tetragonal $\mathrm{Sn}$ and hexagonal $\mathrm{Cu}_{6} \mathrm{Sn}_{5}$.

A reappraisal of the selection of electrochemical parameters for the electrodeposition of tin-rich copper-tin alloys was made by research at Newcastle-upon-Tyne [33] using a $\mathrm{Cu}: S n$ ratio of 1:10 in the MSA electrolyte. The effect of this metal ion ratio in the electrolyte, together with surfactants, on the tin content in the deposit was examined using static and rotating disc electrodes. Cyclic voltammetry showed that inclusion of surfactant in the electrolyte had no effect on the reduction potential of tin which remained at $-0.45 \mathrm{~V}$ vs. SCE. However, the reduction potential for copper decreased from -0.13 to $-0.18 \mathrm{~V}$ vs. SCE, making alloy deposition more facile. Current-time behaviour and anodic stripping voltammetry showed that current efficiency for copper-tin deposition ranged from 92 to 95\%. Deposits containing up to 96 wt.\% tin were obtained using during electrodeposition experiments to obtain high $\mathrm{Sn}$ content at vitreous carbon substrates. $\mathrm{Cu}-\mathrm{Sn}$ alloys consisted of two phases, namely tetragonal tin and the hexagonal $\mathrm{Cu}_{6} \mathrm{Sn}_{5}$ intermetallic.

The effects of a hydroquinone $\left(5 \mathrm{~g} \mathrm{dm}^{-3}\right)$ antioxidant and gelatin as a grain refining agent on the electroplating of $\mathrm{Sn}-\mathrm{Bi}$ alloys from a ca. $1.2 \mathrm{~mol} \mathrm{dm}^{-3}$ MSA bath containing $9 \mathrm{~g} \mathrm{dm}^{-3} \mathrm{Bi}_{2} \mathrm{O}_{3}$ and $30 \mathrm{~g} \mathrm{dm}^{-3}$ $\mathrm{SnSO}_{4}$ at $25{ }^{\circ} \mathrm{C}$ have been studied by Malaysian researchers [35]. A near-eutectic Sn-60.75 wt.\% Bi alloy phase composition could be obtained in compact, and adherent deposits on copper sheets at $18 \mathrm{~mA} \mathrm{~cm}^{-2}$ have been described by Japanese workers [36]. The electroplating bath contained lead phenolsulfonate: 1 to $250 \mathrm{~g} \mathrm{dm}^{-3} \mathrm{~Pb} ; 0.1$ to $250 \mathrm{~g} \mathrm{dm}^{-3}$ tin phenolsulfonate, 20 to $300 \mathrm{~g} \mathrm{dm}^{-3}$ phenolsulfonic acid, 1-50 $\mathrm{g} \mathrm{dm}^{-3}$ polyoxyethylene polyoxypropylene alkylamine; 0.001 to $1 \mathrm{~g} \mathrm{dm}^{-3}$ of a naphthaldehyde derivative and 0.1 to $30 \mathrm{~g} \mathrm{dm}^{-3}$ of a sulfanilic acid aldol derivative or an aqueous solution consisting of lead methanesulfonate: 1 to $250 \mathrm{~g} \mathrm{dm}^{-3} \mathrm{~Pb}, 0.1$ to $250 \mathrm{~g} \mathrm{dm}^{-3}$ tin methanesulfonate, $20-300 \mathrm{~g} \mathrm{dm}^{-3} \mathrm{MSA}: 1$ to $50 \mathrm{~g} \mathrm{dm}^{-3}$ polyoxyethylene polyoxypropylene alkylamine and 0.1 to $30 \mathrm{~g} \mathrm{dm}^{-3}$ of a sulfanilic acid aldol derivative. Each solution contained $<50 \mathrm{ppb}$ of radioactive isotopes. Pb-Sn alloy bump wafer contacts with improved uniformity in height and improved surface smoothness were achieved.

Japanese workers have patented cyanide-free electroplating baths for In-Sn alloys as, e.g., lead-free solder alloys [37]. Typically, the bath contained $100 \mathrm{~g} \mathrm{dm}^{-3} \mathrm{MSA}, 150 \mathrm{~g} \mathrm{dm}^{-3}$ gluconic acid as a chelate, 


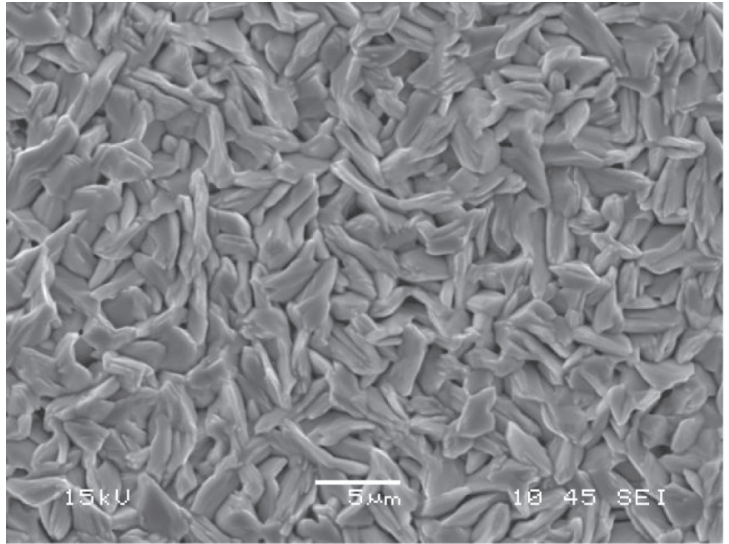

(a)

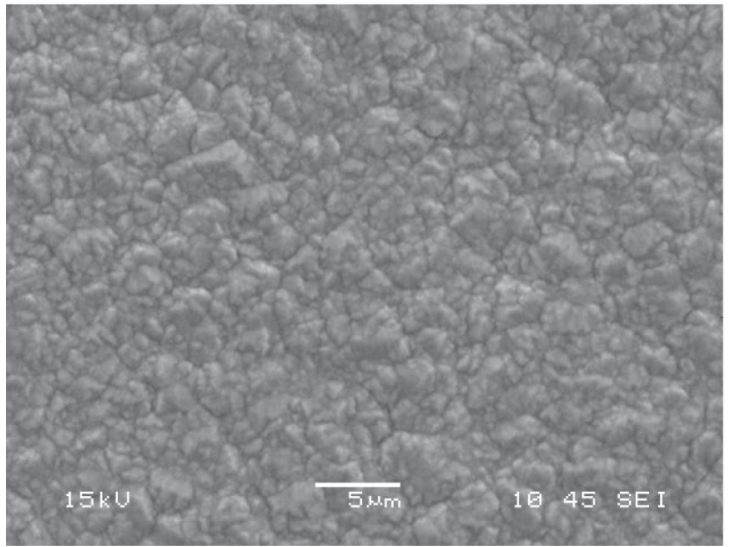

(c)

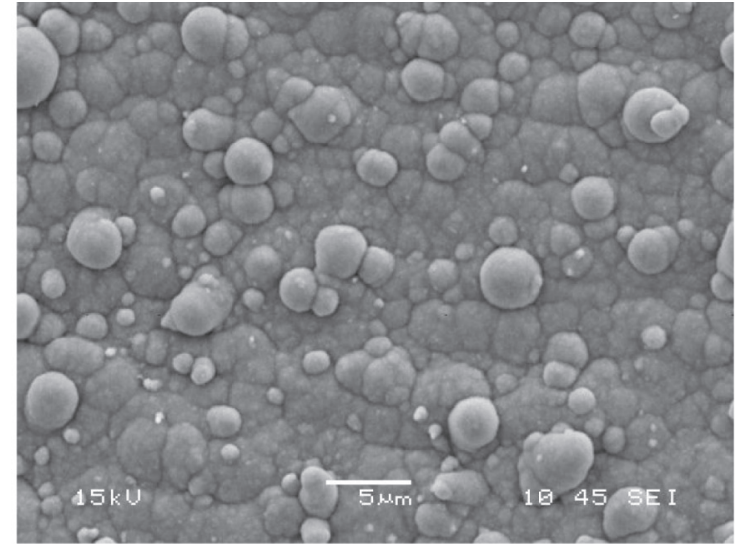

(b)

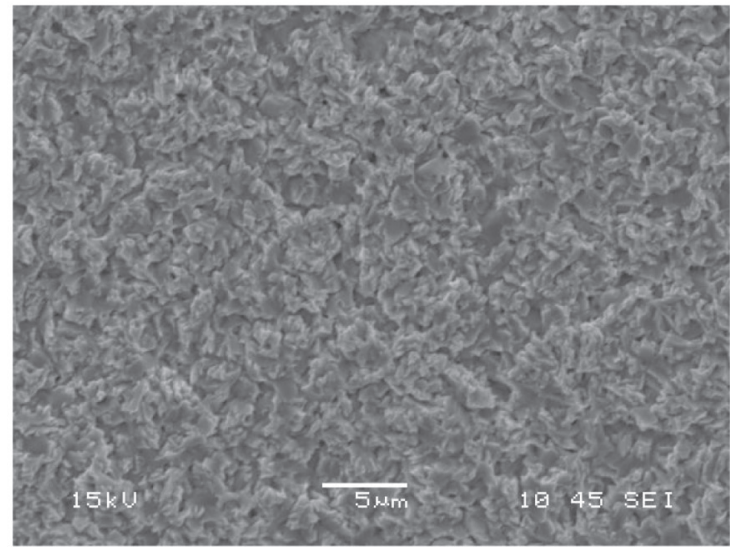

(d)

$5 \mu \mathbf{m}$

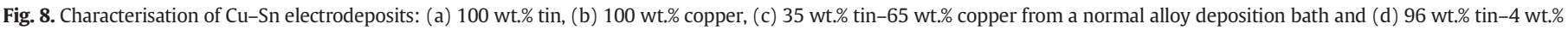
copper from an abnormal alloy deposition bath.

After Low and Walsh [32].

$100 \mathrm{~g} \mathrm{dm}^{-3} \mathrm{KOH}, 27 \mathrm{~g} \mathrm{dm}^{-3}$ tin metastannate and $3 \mathrm{~g} \mathrm{dm}^{-3} \mathrm{In}(\mathrm{III})$, at $\mathrm{pH} 9$.

A ternary $\mathrm{Pb}-\mathrm{Sn}-\mathrm{Cu}$ alloy has been electroplated from MSA as a superconducting coating for linear accelerator components [38].

As part of a study in the authors' laboratory on tin alloy electrodeposition from MSA baths under controlled flow conditions, $\mathrm{Sn}-\mathrm{Bi}-\mathrm{Cu}$ ternary alloys have been prepared [39]. Tin-copper-bismuth ternary alloy deposits containing, e.g., 4\% Sn, 46\% Cu and 50 wt.\% Bi were developed as a lead-free solder replacement.

\subsection{Electroless deposition of metals and alloys}

Electroless deposition is an expensive process compared to electroplating and it is not surprising to find few examples of MSA electroless deposition baths. An exception is electrical conductors and lead-outs for semiconductor components and circuits in the electronics industry. Electroless copper deposition is widely used for printed circuit applications. A new bath based on copper methanesulfonate replacing copper sulphate, EDTA and paraformaldehyde has been developed [40], which is very useful for plating on non-conductors and throughhole plating in printed circuit manufacture. The MSA bath was claimed to realise a faster deposition rate of $3.3 \mu \mathrm{m} \mathrm{h}^{-1}$ compared to the conventional sulphate bath (with a rate of $1.5 \mu \mathrm{m} \mathrm{h}^{-1}$ ) and the bath stability and the quality of the pure copper deposits were very good. Scanning electron microscopy, X-ray diffraction and atomic force microscopy studies were carried out and the crystallite size of the copper was estimated as $134 \mathrm{~nm}$ with a preferred orientation of 200 planes and a surface roughness of only $10 \mathrm{~nm}$.

MSA has also seen used as an electroless plating bath for nickel [41, 42]. In baths formulated with nickel methanesulfonate, MSA and hypophosphorus acid, insoluble orthophosphate [41], it was claimed that insoluble nickel orthophosphite can be avoided to maintain high quality Ni-P deposits. A second paper [42] examined the effect of $\mathrm{pH}$ and temperature on the rate of deposition and phosphorous content from a nickel methanesulfonate bath. The effect of phosphorous content on hardness, wear resistance and corrosion resistance was also studied. SEM and XRD measurements showed nodular and amorphous deposits. As the bath is free from sulphate ions, it was claimed to operate for a large number of turnovers.

There are even fewer examples of MSA baths for immersion deposits, involving open-circuit galvanic displacement of metal such as rapid immersion tin coatings on copper on the inner surface of a copper tube [43]. The deposits were studied by transmission electron microscopy and scanning electron microscopy to explore the factors influencing the uniformity of tin coatings. Despite the fact that tin coatings grow with different morphologies in MSA and hydrochloric acid baths, uniform coatings could be achieved from both of these baths when the substrate surface was clean and smooth. However, differences in the surface-sensitivity, i.e. the dependence of coating uniformity on the substrate surface condition, of plating baths were seen with 
irregular or improperly cleaned substrate. A hydrochloric acid based bath can yield non-uniform coatings on irregular or improperly cleaned substrate, since large-sized grains develop immediately after coating initiation. Such large grains were suggested to orientate to follow the contours of impurity particles or surface irregularities introducing misalignment in grain columns and creating non-uniform coatings. In contrast, an MSA bath was still able to produce uniform tin coatings on contaminated or rough surfaces, as the coating is proposed to accommodate to substrate surface irregularities by the formation of a nanocrystalline zone in the early stages of tin coating.

A large number of metal methanesulphonates that can be useful for the formulation of electroless plating baths have gradually been introduced in the market by TIB chemicals.

\section{Anodic deposition of metal oxides}

A number of metal oxides can be anodically deposited from aqueous baths, including $\mathrm{PbO}_{2}, \mathrm{SnO}_{2}$ and $\mathrm{MnO}_{2}$. Electrochemical deposition offers good control over morphology and phase composition, which is important in applications including batteries, catalysts and oxygen evolving anodes for electrolytic cells $[44,45]$.

Lead dioxide $\left(\mathrm{PbO}_{2}\right)$ coatings were first investigated more than 150 years ago. Earlier studies and applications were, however, limited to coatings formed in situ on lead or lead alloys and anodes of this type always suffered from continuous corrosion of the underlying lead substrate. It is only much more recently that the preparation by electrodeposition of stable lead dioxide layers on inert substrates (typically titanium or carbon) has reignited interest in lead dioxide as an anode material [46]. The reasons for this interest are clear, since lead dioxide coatings have a low cost compared to those based on precious metals, a high electrical conductivity (comparable to that of metals), a high oxygen overpotential and good stability under controlled conditions leading to applications in new processes. From a scientific viewpoint, lead dioxide is a fascinating semiconductor material. Lead dioxide coatings can be prepared with different phase structures, a wide range of surface morphologies and as both doped and undoped materials giving rise to significantly different catalytic activities. In the long term, lead dioxide can contribute substantially to a fundamental understanding of the relationship between coating structure and catalytic activity, which is important to all fields of chemical catalysis.

Lead dioxide may be electrodeposited onto inert substrates such as titanium or carbon from a number of electrolytes in which $\mathrm{Pb}(\mathrm{II})$ is soluble, e.g., sodium/potassium hydroxide when the $\mathrm{Pb}(\mathrm{II})$ is present as plumbite ions or else in nitric acid, perchloric acid, methanesulfonic acid, or in acetate buffer when the $\mathrm{Pb}$ (II) is present as $\mathrm{Pb}^{2+}$ ions. In acidic media, such as MSA, the anode reaction may be written as:

$\mathrm{Pb}^{2+}+2 \mathrm{H}_{2} \mathrm{O} \rightarrow \mathrm{PbO}_{2}+4 \mathrm{H}^{+}+2 \mathrm{e}^{-}$

with oxygen evolution being the main secondary reaction at higher current density. MSA offers a particularly versatile and practical electrolyte as it can also support lead deposition at the cathode, co-deposition of other oxides, such as $\mathrm{MnO}_{2}$ and deposition of a wide range of $\mathrm{PbO}_{2}-$ $\mathrm{MnO}_{2}$ mixed metal oxide compositions at the anode [47].

Lead dioxide deposits can have quite different appearances. It is possible to deposit films with a highly reflective, black, metallic finish [48] although more commonly they have a grey or black matte appearance [47]. When examined by electron microscopy, the diversity of surface morphologies becomes more apparent. Fig. 9 shows SEM images of lead dioxide deposits deposited from MSA baths in the authors' laboratory, which can be made up of crystallites that are very flat, angular, rounded or 'cauliflower' like and their size is another variable $[48,49]$. This is one of the few systematic attempts to correlate the structure as shown by SEM with the properties of the deposits.

Supercapacitors have seen a dramatic surge of interest due to applications in automotive starting, etc. and nanostructured materials offer the biggest chances of success. The expense of high performance precious metal oxide systems has stimulated the search for moderate cost, easily deposited films, including metal oxides on carbon. Lead dioxide nanowire films have been electrodeposited on carbon from MSA baths. The maximum energy density and specific charge capacity of the $\mathrm{C} / \mathrm{PbO}_{2}$ nanowire system increased during the first 50 cycles before reaching their maximum values of $29 \mathrm{~W} \mathrm{~h} \mathrm{~kg}^{-1}$ and $34 \mathrm{~F} \mathrm{~g}^{-1}$, respectively, at a current density of $10 \mathrm{~mA} \mathrm{~cm}^{-2}$ and a depth of discharge (based on the positive electrode material) of 3.8\%. After an initial activation period, the performance of the system remained constant and showed no sign of degradation over 5000 cycles [50].

Nanostructured lead dioxide coatings on titanium or carbon substrates have also found use in the oxidative removal of organic contaminants from environmental waste solutions [51], electrodes for lightweight static batteries [52], and energy storage in soluble lead flow batteries [53].

Mixed metal oxides of controlled structure and phase composition are of interest in batteries, speciality catalysts and electronic conductors and may be conveniently deposited from MSA under facile conditions which lend themselves to larger scale processing. For example, a wide range of $\mathrm{MnO}_{2}-\mathrm{PbO}_{2}$ mixed metal oxide compositions can be anodically deposited at a constant current density of $50 \mathrm{~mA} \mathrm{~cm}{ }^{-2}$ from aqueous MSA at $60{ }^{\circ} \mathrm{C}$, the deposit composition being readily controlled by controlling the concentration of the electroactive species, $\mathrm{Pb}^{2+}$ and $\mathrm{Mn}^{2+}$ [54]. The $\mathrm{Mn} / \mathrm{Pb}$ ratio in the deposit always exceeded that in the electrolyte. For a plain $\mathrm{PbO}_{2}$ deposit, the crystallite size was about $20 \mathrm{~nm}$. For $\mathrm{Mn}-\mathrm{Pb}$ mixed metal oxides, the crystallite size became smaller (ca. 9 to $13 \mathrm{~nm}$ ) depending on deposit composition as seen in Fig. 10a). The smallest crystallite sizes were found in a deposit containing $50 \mathrm{~Pb}-$ $19 \mathrm{Mn}-310$, wt.\% (ratio $\mathrm{Mn} / \mathrm{Pb}=0.38 / 1$ ) prepared from $1.0 \mathrm{~mol} \mathrm{dm}{ }^{-3}$ MSA containing $0.5 \mathrm{~mol} \mathrm{dm}{ }^{-3} \mathrm{~Pb}^{2+}$ and $0.1 \mathrm{~mol} \mathrm{dm}^{-3}$ $\mathrm{Mn}^{2+}$. The authors showed that the deposit composition line lies above that expected from a simple, linear relationship to the metal composition of the bath as shown in Fig. 10b). The less noble Mn oxides (standard electrode potential ca. $+1.23 \mathrm{~V}$ vs. SHE) were preferentially deposited rather than the more noble Pb oxides (standard electrode potential ca. $+1.46 \mathrm{~V}$ vs. SHE). Such metal oxide films provide low cost alternatives to precious metal based coatings for oxygen evolution in electrolytic reactors.

\section{Electrodeposition of conductive polymers}

\subsection{General considerations}

Electrochemical synthesis of conducting polymers offers many advantages over chemical synthesis, including the in-situ deposition of the polymer at the electrode surface, hence the ability to be processed and control of the coating thickness, morphology and degree of polymer doping by control of the quantity of electrical charge passed. Applications of conductive polymer films include electronics components, chemical and biosensors, batteries, corrosion protection and drug release [55-60].

\subsection{Electrodeposition of polypyrrole layers}

The efficient deposition of conductive and electroactive polypyrrole films by direct anodic oxidation of the pyrrole monomer in the presence of an anionic counter ion:

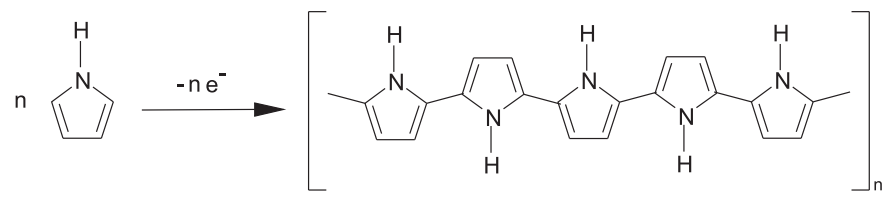

(11) 


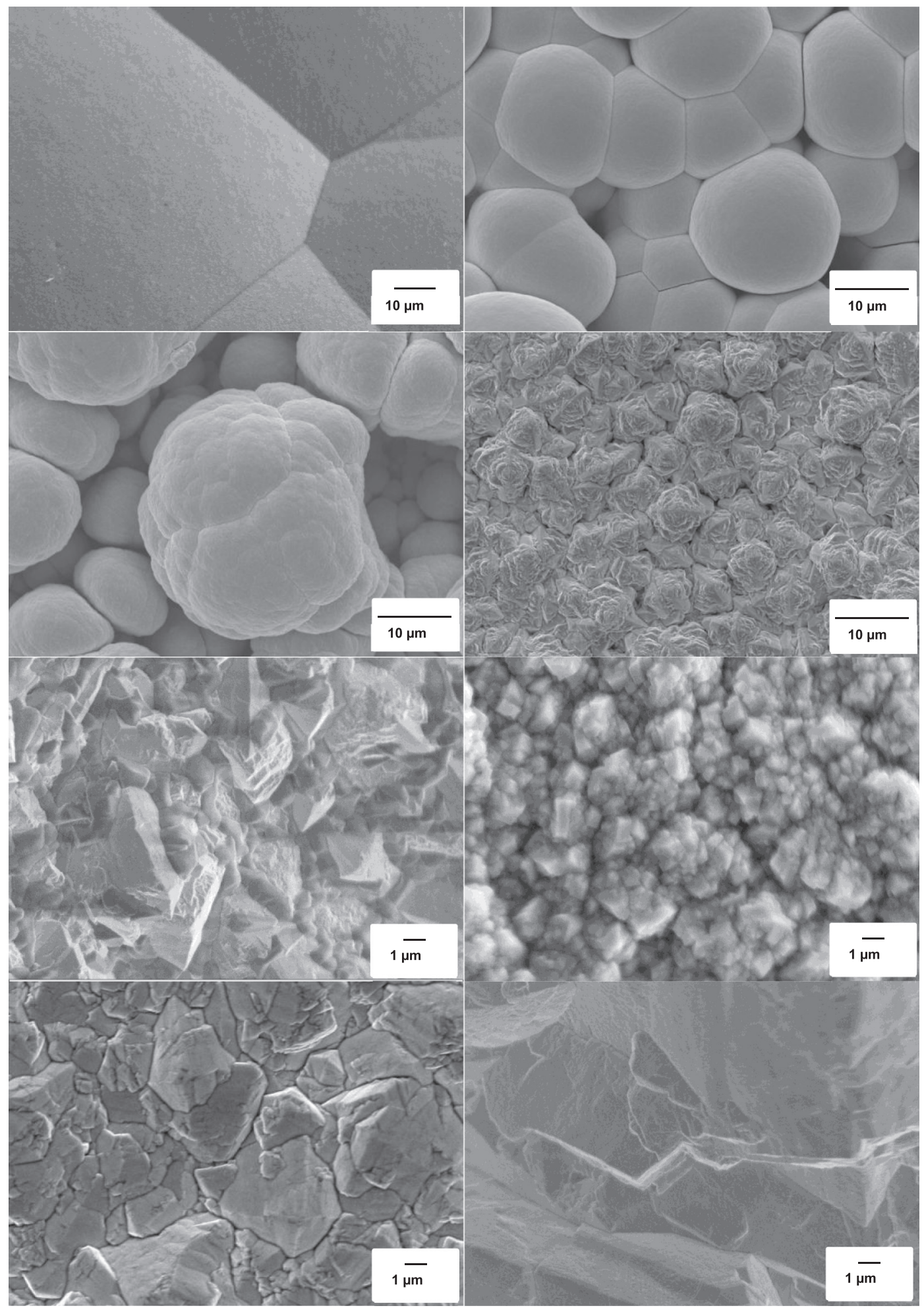

Fig. 9. Diverse morphologies of lead dioxide surfaces anodically deposited from MSA After Li, Pletcher and Walsh [45].

has been known since 1979 [56] and has been extensively reviewed, e.g., [57-60]. Early work (1970s-1990s) used non-aqueous electrolytes such as acetonitrile, which are prone to pick up water and are unsuitable for industrial processing. Since the 1980s, the ability to use aqueous electrolytes, e.g. [61], has been increasingly appreciated. MSA offers an electrolyte which also provides a suitable anion $\left(\mathrm{CH}_{3} \mathrm{SO}_{3} \mathrm{H}^{-}\right)$for film doping to realise compact layers of high electrical conductivity. A recent example is provided in studies by Caramia and colleagues [62] which utilise controlled electrodeposition conditions to produce compact films which may be mechanically peeled from a polished stainless steel substrate as robust, self-standing films, 1-20 $\mu$ m thick.

Fig. 11a) shows the effect of pyrrole concentration on the cyclic voltammograms (CVs). At an electrode potential more positive than $+0.6 \mathrm{~V}$ vs. SCE, the anodic deposition of polypyrrole on the AISI 316L grade 


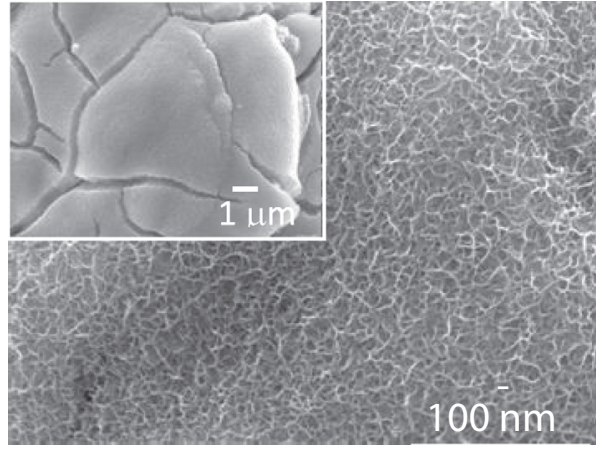

a)

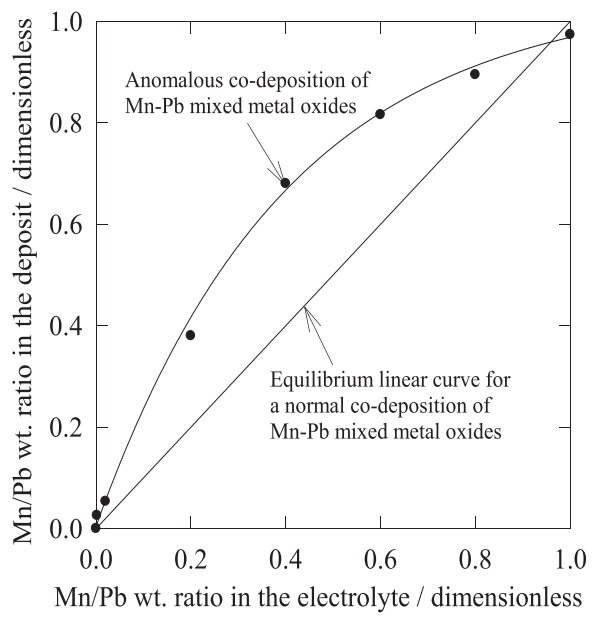

b)

Fig. 10. a) Scanning electron micrograph showing the surface microstructure of a mixed metal oxide $50 \mathrm{wt} . \%,-\mathrm{Pb}-19 \mathrm{wt} . \% \mathrm{Mn}-31 \mathrm{wt} . \% \mathrm{O}$. The layer was deposited on an electrolyte containing $0.5 \mathrm{~mol} \mathrm{dm}{ }^{-3} \mathrm{~Pb}$ (II) in $0.5 \mathrm{~mol} \mathrm{dm}^{-3} \mathrm{CH}_{3} \mathrm{SO}_{3} \mathrm{H}$ and $0.001 \mathrm{~mol} \mathrm{dm}^{-3}$ $\mathrm{Mn}(\mathrm{II})$. Deposition at a constant current density of $50 \mathrm{~mA} \mathrm{~cm}^{-2}$ for $2 \mathrm{~h}$ at $333 \mathrm{~K}$, with agitation by a magnetic stirring bar at $300 \mathrm{rpm}$. The inset shows a lower magnification image. b) $\mathrm{Mn} / \mathrm{Pb}$ weight ratio of the deposit vs. $\mathrm{Mn} / \mathrm{Pb}$ weight ratio in the electrolyte. After Recio, Herrasti, Sires, Kulak, Bavykin, Ponce de León and Walsh [51].

stainless steel substrate initiated fast as evident from the sharp increase in the anodic current density. The recorded current density was high, e.g., tens of milliamperes per square centimetre, compared to typical values of several milliamperes per square centimetre reported in the literature, e.g., [63]. Such a high current density is possible as pyrrole is readily soluble in MSA, e.g. from 0.01 to $1.0 \mathrm{~mol} \mathrm{dm}^{-3}$ pyrrole. A single peak was observed at $+1.2 \mathrm{~V}$ vs. SCE due to the oxidation of the soluble monomer to polypyrrole. At a more positive potential than $+1.6 \mathrm{~V}$ vs. SCE oxygen evolution additionally occurred on the surface of the polypyrrole film. The reduction of polypyrrole to pyrrole did not occur on the reverse potential sweep indicating an irreversible oxidation of pyrrole to polypyrrole. As-expected, when a higher concentration of pyrrole was used, the anodic peak current density increased and could reach several hundred milliamperes. The anodic peak current density, $j_{p}$ increased linearly with concentration of pyrrole, $c$ as shown in Fig. 11b). This linear relationship, indicating diffusion control of film formation, follows the Randles-Sevćik (see Eq. (8)).

Assuming reaction (8) to progress via a mean $n=2.25$, electron loss per monomer unit, $c$ is the pyrrole monomer concentration and $\mathrm{n}$ is the kinematic viscosity of the electrolyte. Using the value of the slope from a plot of peak current density for pyrrole oxidation vs. pyrrole concentration (not shown) the diffusion coefficient of pyrrole in methanesulfonic acid, $D$ was estimated to be approximately $1.4 \pm 0.2 \times 10^{-6} \mathrm{~cm}^{2} \mathrm{~s}^{-1}$ in agreement with typical values of $1.3 \pm 0.15 \times 10^{-5} \mathrm{~cm}^{2} \mathrm{~s}^{-1}$ or $1.25 \pm$
$0.1 \times 10^{-5} \mathrm{~cm}^{2} \mathrm{~s}^{-1}$ found in the literature [60]. Such cyclic voltammetry data define the electrode potential range for polymer deposition and, from the electrical charge envelope under a current-time plot, allow the nominal film thickness to be estimated.

It is also possible to deposit detachable and swollen polymer films having marked porosity via the evolution of oxygen at the surface of the polypyrrole film at potentials more positive than $1.6 \mathrm{~V}$ vS. SCE (typically at current densities of $1-10 \mathrm{~mA} \mathrm{~cm}^{-2}$ ):

$2 \mathrm{H}_{2} \mathrm{O}-4 \mathrm{e}^{-}=\mathrm{O}_{2}+4 \mathrm{H}^{+}$

This is a template-less deposition of polymer due to gas bubble voidage. The realisation of thick (1-10 mm), highly flexible and freestanding polypyrrole film, having a random, micropore structure, on a polished stainless steel substrate using this technique is illustrated in Fig. 11b). The most reproducible conditions used a three-step sequence involving anodic deposition of a thin, compact polypyrrole film, anodic generation of $\mathrm{O}_{2}$ bubbles on the top surface of the film and continuation of polymer deposition on the existing film around the bubbles.

\subsection{Electrodeposition of other polymer layers}

In the processing of conductive polyaniline, a major breakthrough was the discovery that the use of organic sulfonic acids such as camphorsulfonic acid and $p$-dodecylbenzenesulfonic acid as protonic dopants not only provides high conductivity but also confers solubility of PANI in its conducting state (emeraldine salt, ES) in organic solvents such as $m$-cresol, 10 chloroform, and 10 hexafluoroisopropanol. This has opened up a way for preparing conducting blends with controllable conductivity and thermomechanical properties from conducting PANIES and a wide range of thermoplastics and elastomers. Unfortunately, this simple blending with nonacidic, organic solvents is not applicable to aromatic, heterocyclic rigid-rod polymers such as polybenzobisazole, $\mathrm{PBX}$. As an alternative method for processing polyaniline (PANI) from its conducting (protonated) state, vacuum casting of PANI from an MSA solution provided films with electrical conductivity values of about 130-150 S cm ${ }^{-1}$. In addition, blended films of PANI-MSA and poly(p-phenylenebenzobisthiazole), PBZT have been prepared [64]. This process eliminated the need for a subsequent protonation step and had the additional advantage that the conjugated PBZT may provide alternative conducting pathways. Electrical conductivity of the composite films ranged from $100 \mathrm{pS} \mathrm{cm}^{-1}$ to $124 \mathrm{~S} \mathrm{~cm}^{-1}$. Transmission electron micrographs displayed phase-separated regions with PANI forming a continuous network at high concentrations.

Research in Finland has studied preparation of a water-soluble polythiophene, poly-3-(3'-thienyloxy)propanesilfonate, P3TOPS from a polystyrene sulfonic acid electrolyte by sequential; adsorption of anionic and cationic polyelectrolytes at a charged surface [65]. Nanometre accuracy of film thickness was claimed and interpenetration of adjacent layers could prevented using multilayers of P3TOPS and the nonconducting polycation polydiallyl dimethyl ammonium chloride, PDADMA to realise speciality optoelectronic materials.

\section{Electrodeposition of two-phase and composite coatings}

The combination of cathodic deposition and electrophoresis by be used to deposit a family of composite coatings. When it is realised that the coating matrix may be metallic or a conducting polymer in concert with a dispersed particulate phase which may be ceramic, polymeric or even a second metal and the particles might be spheroidal, tubular plate-like or fibres having dimensions from several nanometres [64] to tens of micrometres [65], the enormous and widening scope of coatings for surface finishing becomes clear [66]. MSA provides a versatile bath for such coatings in electrochemical surface finishing, including a range of nanocomposites. 


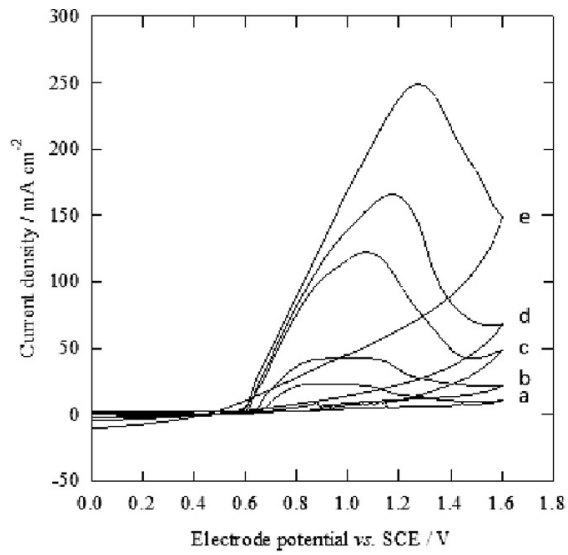

a)

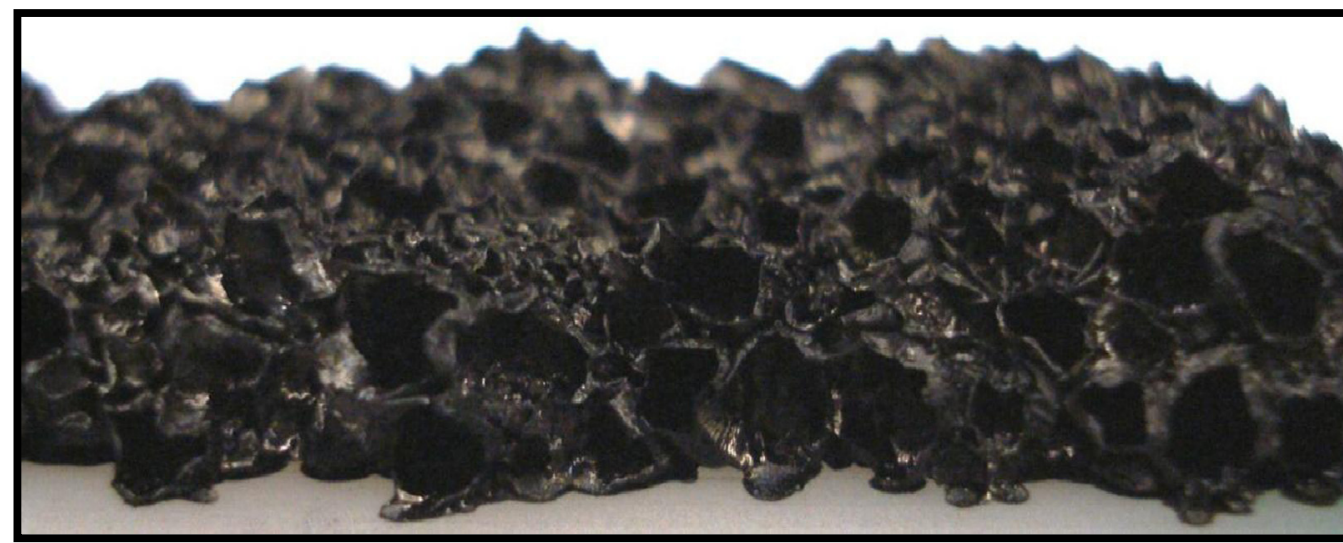

$1 \mathrm{~mm}$

b)

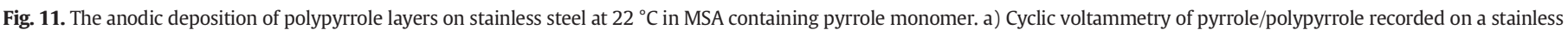

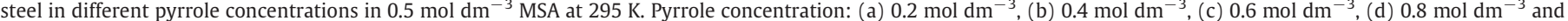

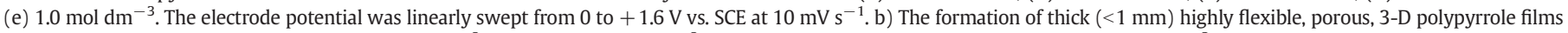

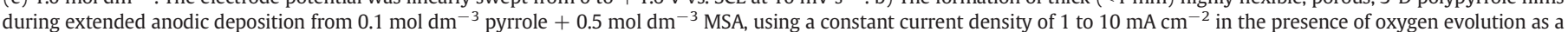

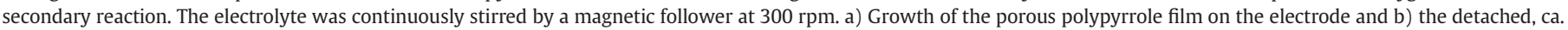
$1 \mathrm{~mm}$ thick polymer film after $60 \mathrm{~min}$ at $10 \mathrm{~mA} \mathrm{~cm}^{-2}$.

After Walsh, Caramia, Low and Ponce de Leon [62].

\subsection{Metal-ceramic coatings}

Electroplating of nanoparticles into coatings is a popular method to extend the versatility of coatings and to confer with multifunctional properties. For example, Fig. 12 shows TEM images of the crosssection of an electrodeposited nickel coating containing nanotubular titanium oxide particles [67]. Nanotubular titanates are clearly embedded into the nickel coating with a reasonably uniform dispersion. Compared with a nickel coating containing irregularly shaped nanosized titanium dioxide particles, this composite coating has demonstrated ca. $20 \%$ reduction in surface friction against steel, (b) $>28 \%$ enhancement in wear resistance in a 3-body water-based abrasive wear test (steel counter body and $5 \mu \mathrm{m} \mathrm{SiC} \mathrm{particles),} \mathrm{(c)}>100 \%$ increases in coating hardness and $(\mathrm{d})>25 \%$ improvement in elastic modulus. It is postulated that the nanotubes in the nickel coating agglomerate to form a crosslinked and mesh-like matrix which led to an enhancement in the dispersion-strengthening mechanism against external load force although this proposition would demand a more detailed imaging of the coating. The tribological properties of such coatings were effectively improved compared with a nickel coating reinforced with irregularly shaped titanium dioxide particles.

A study of electrodeposition of iron-based composite coatings containing zirconia dioxide particles from sulphate and methanesulfonate electrolytes in the Ukraine showed that $<12 \mathrm{wt}$.\% zirconia. Models of the process of $\mathrm{ZrO}_{2}$ particle incorporation into an iron matrix were considered [68].

Metal-polymer [69] and ceramic-polymer [70] composite coatings are also possible from an MSA electrolyte.

\subsection{Metal-polymer coatings}

The preparation of cobalt-perfluoropolyether (PFPE) composite coating with dry lubrication capability has been addressed. An electrodeposited, nanostructured columnar cobalt layer from an MSA bath was subjected to a grain boundary etching then vacuum impregnated with PFPE. The influence of the operating parameters on deposition were considered [69]. The authors did not consider direct 


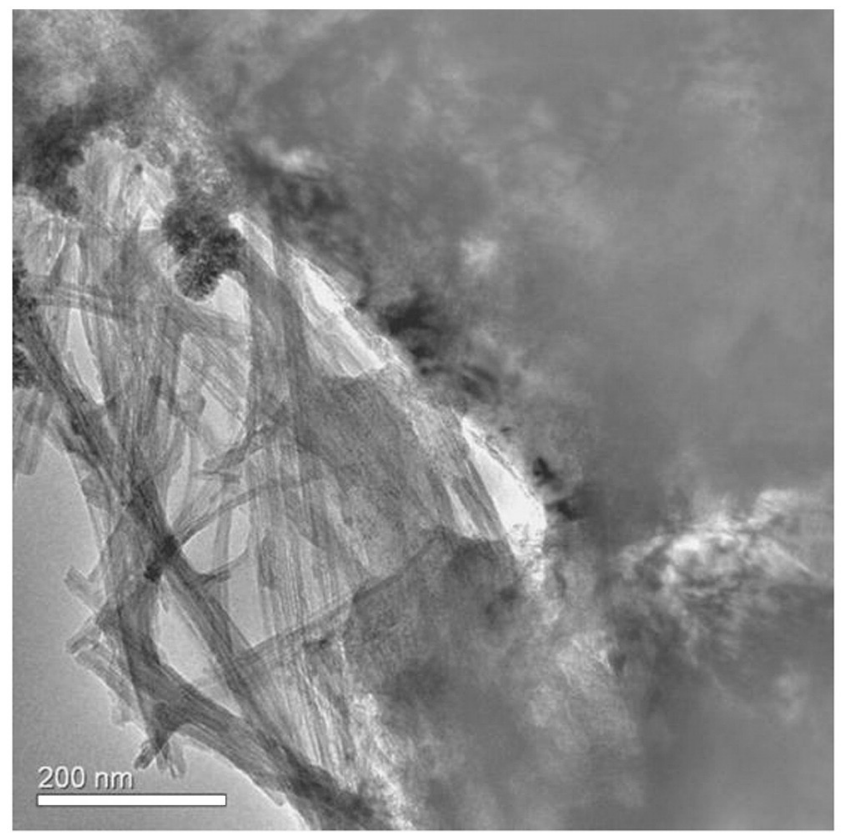

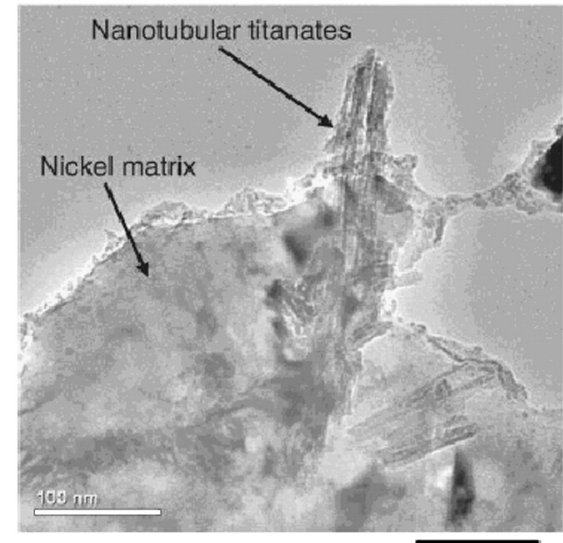

$100 \mathrm{~nm}$

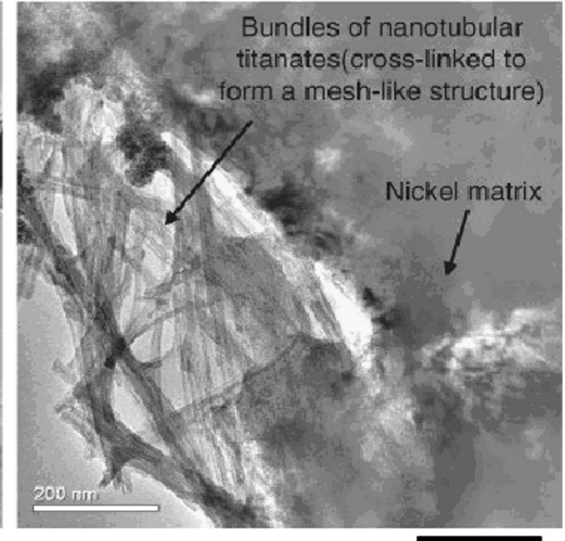

$200 \mathrm{~nm}$

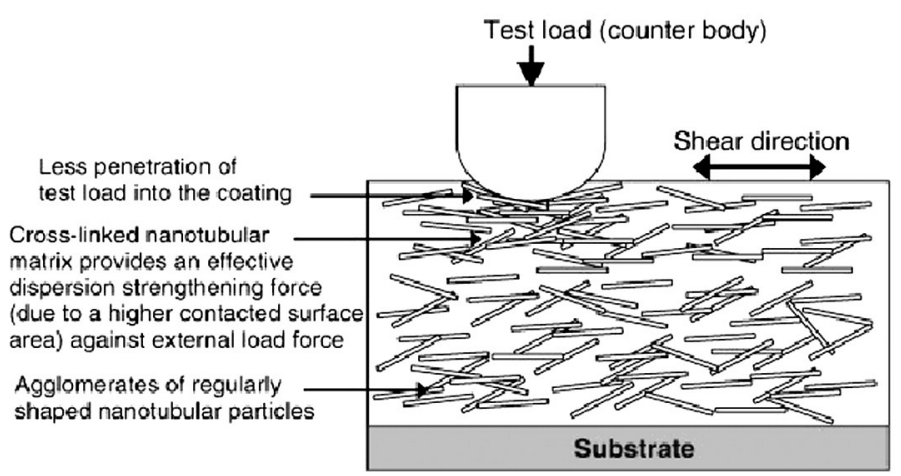

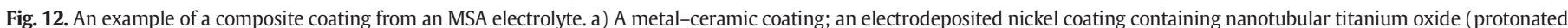

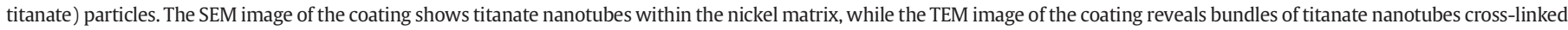
to form a mesh-like structure; the sketch indicates strengthening and support mechanisms within the coating.

After Low, Bello, Wharton, Wood, Stokes and Walsh [67].

electrodeposition of the metal with included PTFE particles although this is well established by combining electroplating of metal with electrophoretic particle incorporation via judicious selection of surfactants to achieve a stable polymer dispersion, in the case of $\mathrm{Ni}-$ PTFE from acid sulphate and sulfamate baths [70], making MSA an easy choice of electrolyte to realise a single bath for composite deposition [71].

\subsection{Polymer-ceramic coatings}

The combination of electrodeposition and electrophoresis can be used to provide a convenient single electrolyte. For example, anodic electropolymerisation of pyrrole and electrophoretic co-deposition of hydrothermally-prepared titanate nanotubes suspended in the electrolyte has been demonstrated in the authors' laboratory using a 
modified Watts nickel (acid sulphate) bath [72]. The use of MSA electrolytes would enable a wider choice of included particles and improved control over the deposit structure.

Polyaniline has been deposited from MSA via simple solvent evaporation to coat glassy carbon particles as the stationary phase in ionexchange chromatography. The typical film thickness varied between 50 and $400 \mathrm{~nm}$. The sulfonic acid doping was important in controlling polymer electronic conductivity [73].

\section{Anodising of metals}

Commonly, sulphuric or phosphoric acids are used for routine anodising of aluminium and valve metals such as titanium and tantalum [73-76]. MSA provides a particularly versatile electrolyte for control over the morphology of the porous array [77].

\subsection{Arrays of nanopores}

The literature largely considers anodising of titanium since highly ordered arrays of nanopores (nanotubes) can be achieved from an acid electrolyte containing F-ions at a constant cell potential [74]. In particular, many studies have been carried out by the groups of Grimes [75] and Schmucki [76], mostly using sulphuric and phosphoric acids.

A contribution from our laboratory has preferred an MSA electrolyte for improved electrochemical control to achieve robust, hexagonally templated nanopore arrays of $\mathrm{TiO}_{2}$ on a $250 \mu \mathrm{m}$ thick titanium foil (Fig. 13) [77]. A two stage anodising process was used in a single stirred electrolyte containing $5 \mathrm{~mol} \mathrm{dm}^{-3} \mathrm{MSA}+0.5 \mathrm{wt} . \% \mathrm{NH}_{4} \mathrm{~F}$ at $22^{\circ} \mathrm{C}$. In the first stage, a cell voltage of $20 \mathrm{~V}$ was used to initiate pore nucleation and early growth; the second stage used $>30 \mathrm{~V}$ to grow the oxide pores, typically to a diameter of ca. $100 \mathrm{~nm}$ and length $<400 \mathrm{~nm}$ with a pitch of $50 \mathrm{~nm}$ and a tube wall thickness of ca. $10 \mathrm{~nm}$ within a 2 hour time. The formation of $\mathrm{TiO}_{2}$ nanotubes occurs via simultaneous electrochemical formation of oxide via the reaction:

$\mathrm{Ti}+2 \mathrm{H}_{2} \mathrm{O} \rightarrow \mathrm{TiO}_{2}+4 \mathrm{H}^{+}+4 \mathrm{e}^{-}$

and chemical dissolution of the oxide by fluoride ion attack:

$\mathrm{TiO}_{2}+6 \mathrm{~F}^{-}+4 \mathrm{H}^{+} \rightarrow \mathrm{TiF}_{6}^{2-}+2 \mathrm{H}_{2} \mathrm{O}$.

In the initial stage of anodising, a compact layer of titanium dioxide was formed on the $250 \mu \mathrm{m}$ thick titanium foil. This layer could be dissolved to form a soluble hexafluorotitanium complex anion in the presence of fluoride ion. It is a localised dissolution process where breakdown of the oxide layer occurred randomly on the surface, and disordered pores are formed. At this stage, a compositional gradient is established between the top and bottom of the pores. This gradually resulted in the formation of ordered pores distributed homogeneously over the top surface. These pores continued to grow inward to the titanium foil, leading to the formation of a nanotubular array. A 'barrier' layer remained between the pore bottom and the titanium substrate. At the pore mouth, dissolution of the oxide continued. In general, electroplated nanotubes and nanowires of materials can be readily synthesised using anodized nanotubular structures.

\subsection{Metal decorated nanopores}

Au sputtering of anodised nanoporous array structures may be used to enhance chemical stability and catalytic properties. Such Au-coated anodised nanopore arrays are shown in Fig. 13. Such nanoporous arrays have been demonstrated for peroxide reduction [78] and oxidation of borohydride ions [79], the cathode and anode reactions in a high performance borohydride fuel cell.

In some catalytic applications, it is important to intimately incorporate precious metals inside nanostructures. Examples are provided by the work of Bavykin and colleagues, including gold, platinum and ruthenium nanoparticles by, e.g., chemical reduction of the metal ions adsorbed into the nanotube [80-82].

\section{Developing coatings and layers}

\subsection{Nanostructured films}

The move to nanostructured surface coatings has been driven by several factors.

1. The promised benefits of nanostructured materials, compared to classical microstructured ones, such as improved compactness, hardness, wear resistance corrosion resistance and, in some cases, better electrical, optical and magnetic characteristics

2. The discovery and popularisation of timely nanomaterials, particularly carbon nanotubes and graphene together with lower cost materials which are easier to fabricate and process, such as titanium oxides

3. The growing realisation that natural materials often utilise nanostructure to achieve exciting engineering properties, including hardness, toughness and controlled tribology, which has given rise to biomimetics as a growth discipline in materials engineering. Examples include layered materials such as graphenes and tungsten disulphide.

4. The improved imaging of surfaces possible by probe microscopy, ion beam and probe techniques

5. The ability to extend the versatility of nanostructured surfaces by, for example, adsorption of solid state lubricants, functionalization and overcoating using a wide range of techniques.

The wide scope of electrochemical approaches to nanostructured surfaces has already been indicated in Fig. 3. Diversity is shown by the use of anodic, cathodic and open-circuit conditions, electroplating, anodising, electrophoresis and electroless plating as techniques and layers which range from single component metals through to complex, composite multilayer or nanostructured thick coatings. The role of electrochemical techniques in realising such surfaces has been reviewed by the present authors [80] while others have considered the particular cases of electroplating [81], anodising [82,83] and nanocomposite plated coatings [67].

Several semiconductor and photoconductor materials have been deposited from MSA using a combination of electroplating and electrophoresis. For example, a US patent concerns $\mathrm{Cu}_{\mathrm{x}} \mathrm{Se}$, CuSe, $\mathrm{In}_{2} \mathrm{Se}_{3}, \mathrm{CuIn}_{2}$, CuInSe $\mathrm{C}_{2}$ and $\mathrm{CuGaSe} \mathrm{C}_{2}$ films deposited from aqueous MSA at $5-20 \mathrm{~mA} \mathrm{~cm}^{-2}$ for use in solar cells [84].

New possibilities in the design of gold-containing electrochemical coating systems for electronic applications are given by the incorporation of gold nanoparticles in metal-matrix-systems. The major problem for the application of nanoparticles is the strong agglomeration of the particles in the electrolyte solutions, preventing the incorporation of nanosized dispersants. A new concept for the deposition of nano dispersed layers, which overcomes this agglomeration problem, is the application of core-shell systems. Using these systems, it becomes possible for the first time to incorporate metal nanoparticles into electrodeposited metal layers to form metal nanoparticle metal matrix systems. The advantage of such layers is the formation of nanocomposite materials far away from thermodynamic equilibrium. Especially for the combination of gold nanoparticles in a nickel matrix, a strategy becomes available for the manufacturing of temperature-stable nanocomposite structure. By incorporating the precious metal material into the nickel matrix as the main electrodeposit, and reducing the top gold layer thickness, gold consumption may be reduced. Studies by German researchers [85] have used a sulphite containing, MSA based nickel bath containing conventional additives to deposit on $2 \mathrm{~cm}^{2}$ area copper cylinder electrodes rotating at 250-1000 rev $\mathrm{min}^{-1}$. The $1 \mathrm{~mol} \mathrm{dm}^{-3}$ MSA nickel sulphamate bath contained saccharin for stress reduction, particularly to avoid crack formation in the deposits along with a boric acid buffer ( $\mathrm{pH} 4$ ), naphthalene sulfonic acid, sodium dodecyl sulphate 

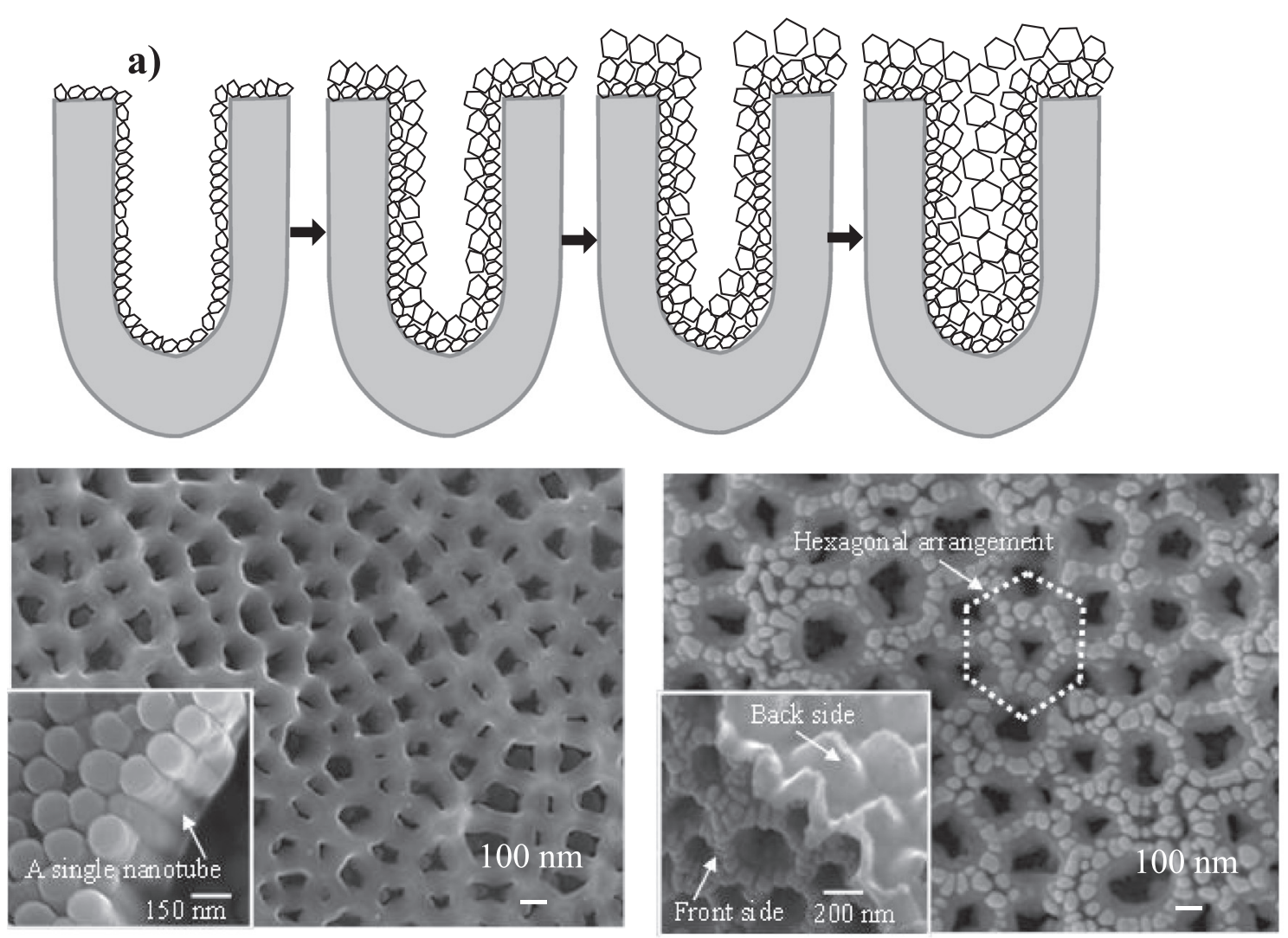

b) 'as-formed' $\mathrm{TiO}_{2}$ nanotubular array

d) 20 minutes Au deposition

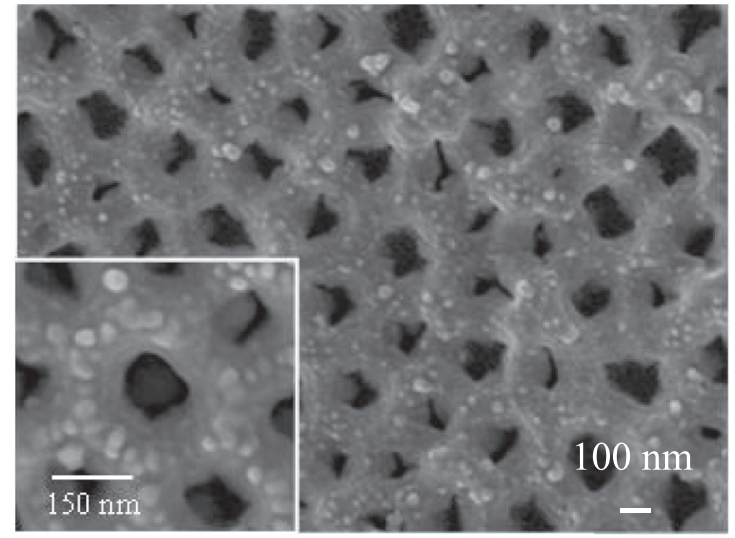

c) 10 minutes Au deposition

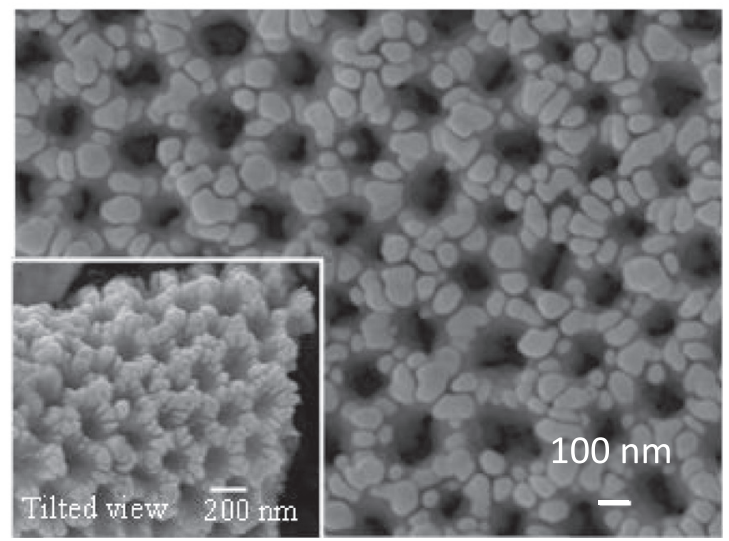

e) 30 minutes Au deposition

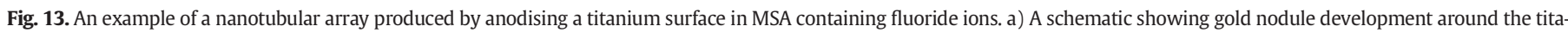

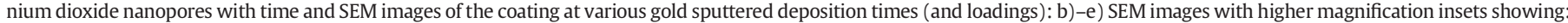
b) as-formed $\mathrm{TiO}_{2}$ nanotubular array (and coating mass density) after $\left.\left.0 \mathrm{~min}, \mathrm{c}\right) 10 \mathrm{~min}\left(69 \mu \mathrm{g} \mathrm{cm}{ }^{-2}\right), \mathrm{d}\right) 20 \mathrm{~min}\left(164 \mu \mathrm{g} \mathrm{cm}{ }^{-2}\right)$ and e) $30 \mathrm{~min}\left(179 \mu \mathrm{g} \mathrm{cm}{ }^{-2}\right.$ ). After Walsh and Ponce de Leon [71].

(anionic surfactant) and triton X-100 surfactant, and phenolphthalein, representing a complex electrolyte to maintain. Gold nanoparticles (average diameter 6-10 $\mathrm{nm}$ ) were produced by chemical/electroless deposition from a solution containing borohydride as a reducing agent then pre-coated in a polyethyleneimine polyamidoamine polymer. By combination of gold nanoparticles with the polymer PEI-PAMAM it is possible to stabilize a clear solution of metal nanoparticles in electrolyte solutions of high ionic strength. The long term stability of the solution depends on the molar ratio between polymer and gold. Only solutions with a molar ratio up to 1:30 showed good long term stability, since there is no diffusion between nickel and gold. The current density was changed between 0.2 and $8 \mathrm{~A} / \mathrm{dm}^{2}$. The gold nanoparticles are very homogeneously distributed on the surface and inside the coatings, gold incorporation of 2-3 wt.\% in the nickel layers was achieved by a low gold concentrations in the electrolyte of only $70 \mathrm{mg} \mathrm{dm}^{-3}$ [85].

\subsection{Multi-layered coatings}

Multi-layered deposits can considerably widen the scope of electrodeposited coatings and may often be achieved in a single bath using potential- or current control [86]. In the case of anodic deposition of metal oxides, the authors' laboratory has shown that alternate layers of $\mathrm{PbO}_{2}$ can be continuously deposited on a carbon-polymer composite from an MSA bath simply by pulsing the constant current flowing. 


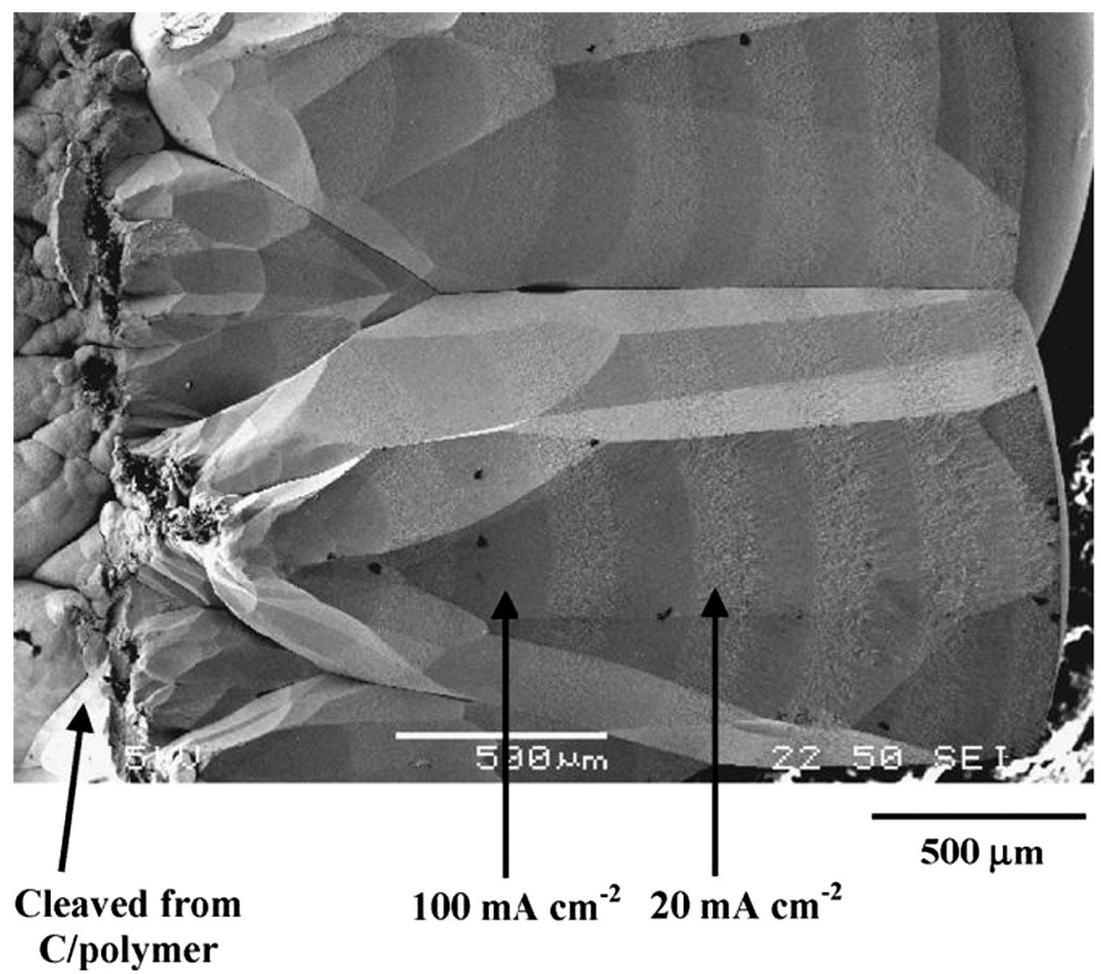

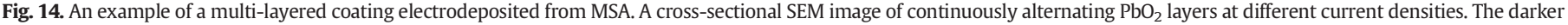
layer was deposited at $20 \mathrm{~mA} \mathrm{~cm}{ }^{-2}$ and consists mainly of a $\alpha$ - and $\beta-\mathrm{PbO}_{2}$ mixture, while the lighter layer was deposited at $100 \mathrm{~mA} \mathrm{~cm}^{-2}$ and consists of pure $\beta-\mathrm{PbO}_{2}$. After Pletcher, Zhou, Kear, Low, Wills and Walsh [46]

Fig. 12 provides an example of the thick and compact deposits achieved, which have found use in soluble lead flow batteries for energy storage [53] (Fig. 14).

\subsection{Electrophoretic deposition of graphene and graphene oxide}

The scientific literature has mushroomed due to interest in graphene since the 2010 Physics Prize Nobel Laureate work of Geim, Novoselov and their colleagues on mechanical peeling and characterisation of graphene layers [87]. In order to produce and process this material for surface engineering, appropriate technology must be developed, however, to easily and economically synthesise graphene products in a form where they can be functionalised then dispersed in a manner facilitating surface coating in a practical, scale-able manner. In the case of aqueous processing, the electrochemical processing of graphene has recently been reviewed [88]. Following this lead, several groups have reported electrochemical treatments for the exfoliation of graphene sheet. For example, Chinese and Taiwanese workers have used cathodic treatment of graphite in an alkaline ammonium sulphate electrolyte [89]. The graphene sheets produced through this process were considered as good precursors for the preparation of graphene sheet-polymer based nanocomposites. A process for large scale electrolytic synthesis of graphene flake has also been reported [90]. Ionic liquid electrolytes have been suggested [91] but pose problems of expense and maintenance for routine processing.

Our laboratory has developed a one-pot, aqueous electrochemical process (Fig. 15a) in $2 \mathrm{~mol} \mathrm{dm}{ }^{-3} \mathrm{MSA}$ at room temperature $\left(23^{\circ} \mathrm{C}\right.$ ) [92] which uses a highly ordered pyrolytic graphite (HOPG) anode and a platinised titanium cathode in an undivided cell to achieve a number of steps:

1. anodic intercalation of graphite by ions and molecular hydrogen to realise graphene oxide in nanostructured flake form,

2. dispersion of the graphene oxide nanoparticles in the MSA and

3. stabilisation of the colloid then
4. electrophoretic coating of the oxide or its reduction product, graphene onto a cathode from the sol electrolyte.

Fig. 15b) shows the typical morphology of graphene oxide flake from this process [92]. In the final step, the dispersion may be used to obtain reconstituted graphene films by electrophoresis, acting as an anodising electrolyte to achieve graphene-oxide filled metal oxide (e.g., $\mathrm{TiO}_{2}$ arrays of ordered nanopores) or have metal ions added to achieve electrodeposited composite coatings.

Boron nitride nanosheet (BNNS) research has been limited by the lack of an efficient method to prepare BNNS. In a recent study, a facile and efficient method for the fabrication of BNNS through liquidphase exfoliation of hexagonal boron nitride particles (h-BNs) in MSA is considered [93]. The resultant BNNS could be readily dispersed in a number of organic solvents, such as $\mathrm{N}$-methyl-2-pyrrolidone. Transmission electron microscopy and atomic force microscopy confirmed that the obtained BNNSs were mainly single or few-layered with a thickness $<3 \mathrm{~nm}$. X-ray photoelectron and infrared spectroscopy revealed that almost no compositional change occurred in BNNS during the exfoliation process. The BNNS is promising in a number of important applications as demonstrated in this study of poly $\left[2,2^{\prime}\right.$-(p-oxydiphenylene)-5,5'bibenzimidazole] (OPBI)/BNNS composites, where the composites showed superior mechanical and thermal properties as compared to neat OPBI and hexagonal-BN reinforced ones.

\subsection{Hierarchical coatings}

Our fundamental understanding of nanostructured coatings improves alongside techniques for achieving such surfaces and this section considers an example of a more complex nanostructure having distinct phases in its structure, which are arranged in a hierarchical fashion. An example is provided by the ability to position hydrothermally synthesised titanium oxide nanotubes within a nanotubular $\mathrm{TiO}_{2}$ array on a titanium foil substrate using anodic electrophoresis from an oxalic 
acid-titanate nanotube sol containing an anionic surfactant [94]. Cationic electrophoresis is also possible using a cationic surfactant and this opens up the possibility of achieving metal-hybrid nanoporous ceramic structures as robust coatings using, for example MSA-based electrolytes which can support titanate sols as well as high metal solubility to facilitate electroplating or anodising. There is also the possibility of inserting active materials, such as medically active compounds, corrosion inhibitors or solid state lubricants into the inner tubes and arranging the outer tube structure to facilitate controlled release with time or in response to changing service conditions.

\section{Conclusions}

A number of general conclusions may be reached regarding MSA electrolytes:

1. Surface finishing applications have included cleaning solutions, electroplating bath additives and baths for many surface finishes and coatings.
2. MSA electrolytes can be successfully used for many types of electrochemical coating techniques such as electroplating, anodising, and electrophoresis.

3. The diverse range of coating materials includes metals, alloys, composites and conductive polymers, which may be realised by single or combined application of electroplating, anodising and electrophoresis.

4. A very wide range of coating thickness is possible, ranging from monolayers to several millimetres on substrates which vary in size from a pin head to large engineering structures.

5. Traditional, single metal electroplated layers, such as copper, tin and lead have been expanded by plated metal alloys (e.g., $\mathrm{Sn}-\mathrm{Pb}, \mathrm{Bi}-\mathrm{Sn}$, $\mathrm{Cu}-\mathrm{Sn}, \mathrm{Cu}-\mathrm{Bi}-\mathrm{Sn}$ )-and composites (e.g., Ni-titanium oxides) as well as conductive polymers (e.g., polypyrrole, polythiophene) and anodised nanopore arrays (e.g., $\mathrm{TiO}_{2}$ ).

6. Existing and expanding uses include the industrial sectors of engine bearings, electrical solders and electrical contacts.

7. Developing applications. Nanostructured materials for catalysis, portable batteries (including lithium cells), redox flow batteries for grid

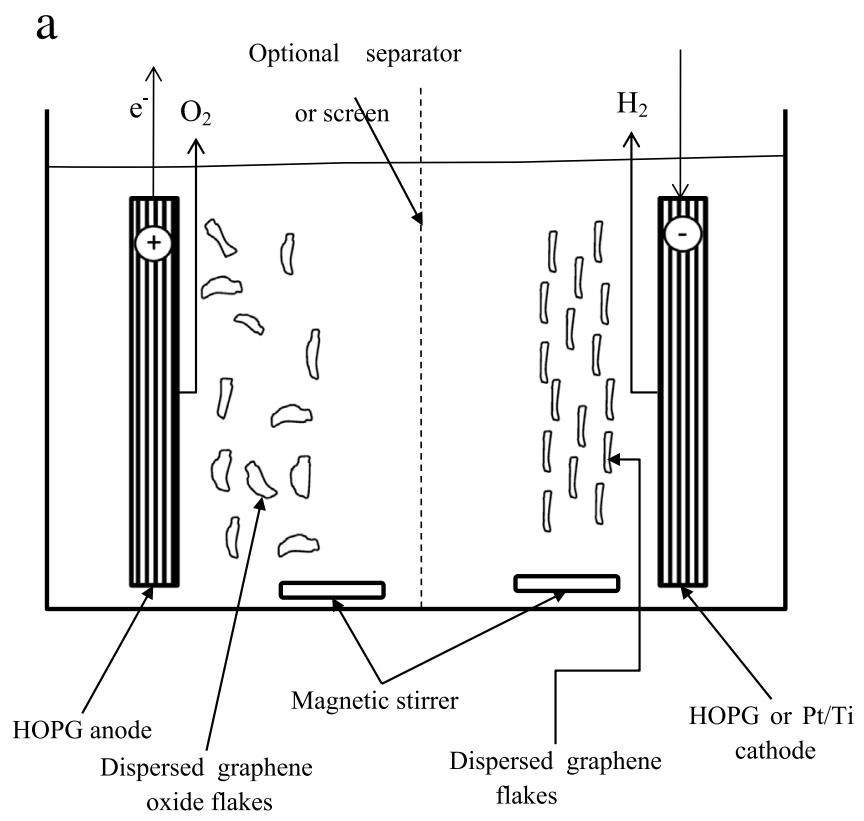

b
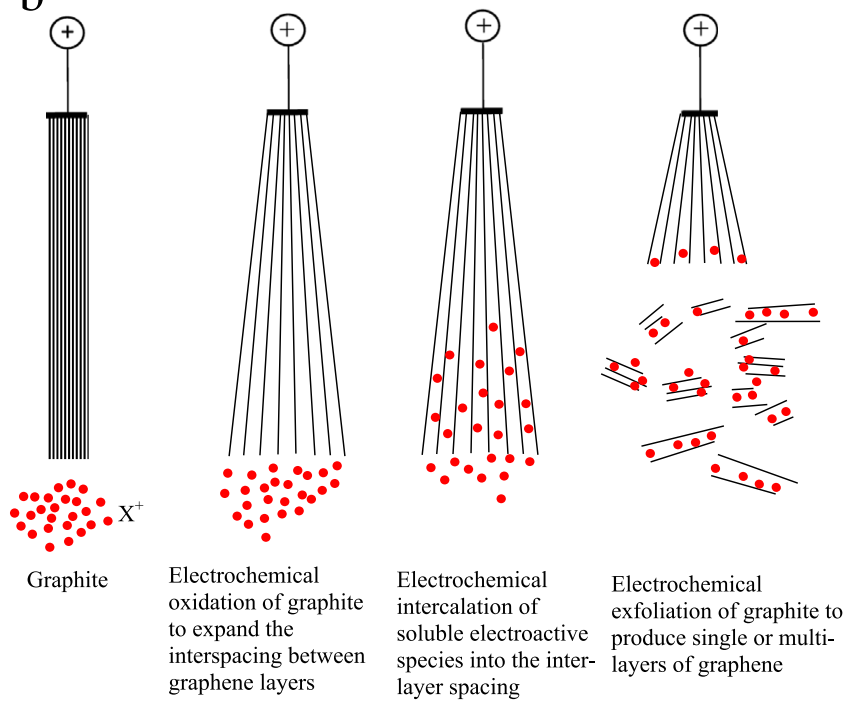

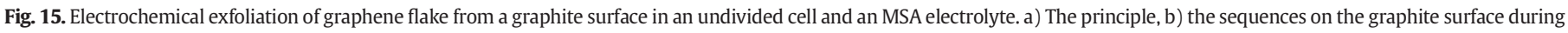
the one-pot process $[88,90]$ and c) SEMs showing typical morphology of the nanoflake product deposited on a porous nickel foam surface. After Walsh et al. [92]. 
C

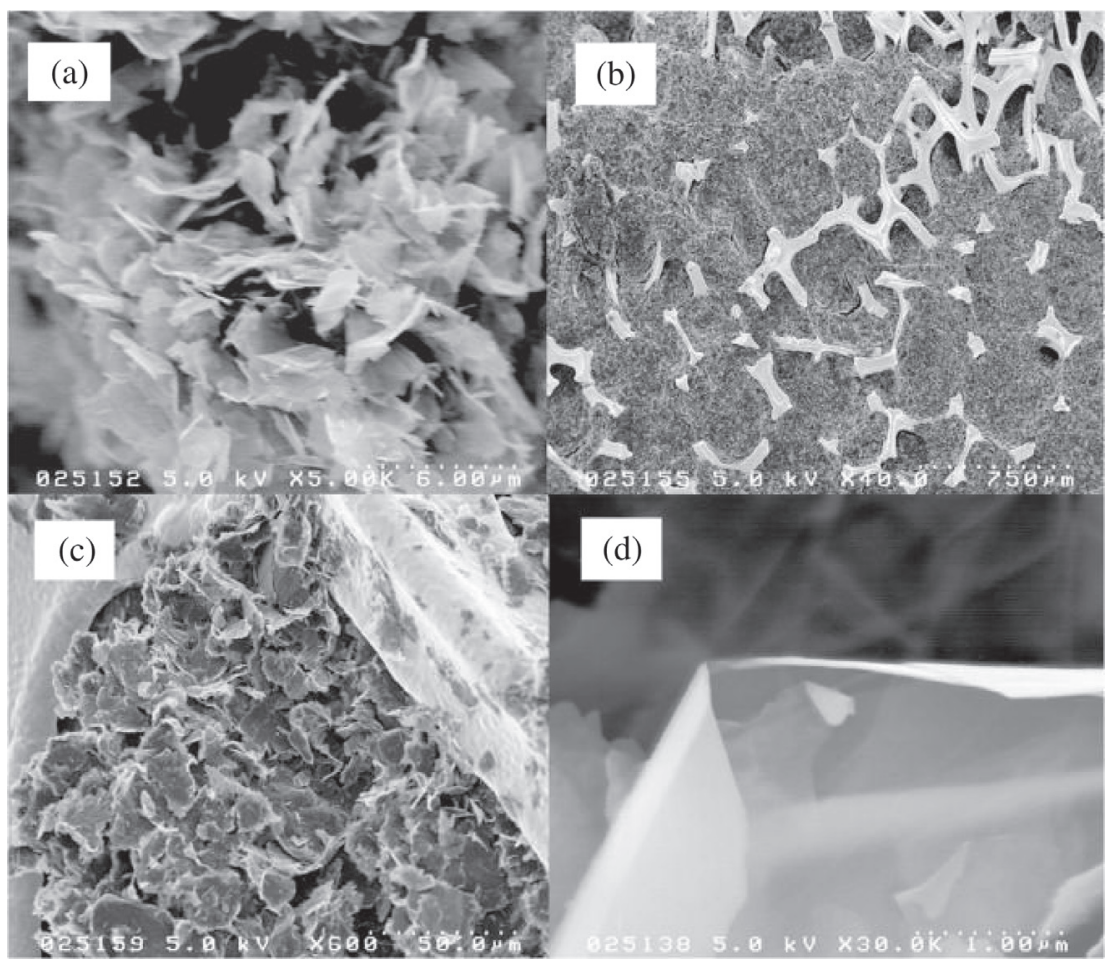

Fig. 15 (continued).

energy storage and load levelling together with energy conversion in fuel cells and supercapacitors. Very recent literature shows evidence of developments in chemical and biochemical sensors and chemical catalysts.

8. Nanostructured films are developing fast and are expanding the scope for, and utility of, MSA electrolytes.

9. In contrast to many techniques for modification of engineering surfaces, the scale of operation can be readily varied and often conventional processing facilities, such as anodising and electroplating lines can be deployed.

\section{Further research}

Further studies are needed on MSA electrolytes in the following areas of surface finishing:

1. Electroplating. A wider range of bath additives and their interaction should be studied to develop improved metal and alloy coatings.

2. Electroless deposition. In order to exploit the combined advantages of MSA electrolytes and electroless metal deposition, it will be necessary to study bath compositions, operating conditions, and bath stability, particularly for electrolytes containing surfactants to aid dispersion or electrophoresis or baths having suspended particles which might result in spontaneous bath decomposition.

3. Anodising. Precision templated arrays are facilitating drug release while the versatility of MSA facilitates hierarchical coatings and 'one-pot', processes having a low environmental impact.

4. Composite coatings. Metal-polymer-ceramic layers and those involving nanoparticle dispersions; more sophisticated anodised surfaces, e.g., impregnated with monitoring materials or solid state lubricants and core-shell, metal-polymer nanoparticles have begun development.

5. The non-toxic nature and the ability to increase the solubility in MSA together to its high biodegradability are the factors that most likely led to further uses of the acid in electroplating and other applications. Over the last decade, an increasing number of reported articles using MAS have appeared.

6. There are very few examples of direct comparisons of coatings from MSA and other electrolytes in the literature, making the competitive position of MSA poorly defined in relation to more traditional electrolytes in surface finishing. This is clearly an area needing focused research studies.

\section{Nomenclature}

$\begin{array}{lll}\text { Symbol } & \text { Meaning } & \text { Units } \\ c & \text { Concentration of electroactive species } & \mathrm{mol} \mathrm{cm}^{-3} \\ D & \text { Diffusion coefficient of electroactive species } & \mathrm{cm}^{2} \mathrm{~s}^{-1} \\ \mathrm{C} & \text { Faraday constant } & \mathrm{C} \mathrm{mol}^{-1} \\ \mathrm{Dimensionless}_{a} & \text { Acid dissociation constant } & \mathrm{A} \mathrm{cm}^{-2} \\ j_{\mathrm{L}} & \text { Limiting current density } & \mathrm{A} \mathrm{cm}^{-2} \\ j_{p} & \text { Peak current density in cyclic voltammetry } & \mathrm{cm} \mathrm{s}^{-1} \\ k_{\mathrm{c}} & \text { Kinetic rate constant } & \mathrm{g} \mathrm{mol}^{-1} \\ M & \text { Molar mass } & \mathrm{Dimensionless}^{-1} \\ n & \text { Number of electrons involved in the written reaction } & \mathrm{V} \mathrm{s}^{-1} \\ v & \text { Linear potential sweep rate } & \mathrm{cm}^{2} \mathrm{~s}^{-1} \\ \nu & \text { Kinematic viscosity } & { }^{\circ} \mathrm{C} \\ T_{b p} & \text { Boiling point } & { }^{\circ} \mathrm{C} \\ T_{m p} & \text { Melting point } & \end{array}$

Abbreviations

$\mathrm{CV}$

HOPG

MSA

RCE

$\mathrm{RCH}$

RDE

SEM

TEM
Cyclic voltammetry Highly ordered pyrolytic graphite Methanesulfonic acid Rotating cylinder electrode Rotating cylinder Hull Rotating disc electrode Scanning electron microscopy Transmission electron microscopy 


\section{Acknowledgements}

The preparation of this review has benefitted from early material presented by FCW at the National Association for Surface Modification (NASM) symposium at Manchester on 13 April, 2010. The authors gratefully acknowledge work carried out by research colleagues in their laboratory over the last ten years, including Dr Vicenzo Caramia, Mr Derek Egan, Dr Gareth Kear, Dr Xiaohong Li, Dr John Low, Mr Miguel de la Toba-Corral and Dr Ignacio Sires together with valued collaborations involving their colleagues Prof Derek Pletcher and Dr Richard Wills.

\section{References}

[1] S. Patai, Z. Rappoport, The Chemistry of Sulphonic Acids, Esters and Their Derivatives, Wiley and Sons, New York, 1991. 251.

[2] M.D. Gernon, M. Wu, T. Buszta, P. Janney, Green Chem. 1 (1999) 127-140.

[3] R. Guertin, US Patent. 3,626,004, 1967, assigned to Pennwalt Corporation.

[4] "Lutropur ${ }^{\circledR}$ - the friendly acid", sales information, BASF SE, Home Care \& Formulation Technologies Europe, Carl-Bosch-Straße 3867056 Ludwigshafen, Germany; (2014) email: industrial-formulators-eu@basf.com; http://www.innovadex.com/.

[5] J.P. Guthrie, Can. J. Chem. 56 (1978) 2347-2354.

[6] D.B. Roitman, J. McAlister, F.L. Oaks, J. Chem. Eng. Data 39 (1994) 56-60.

[7] C. Rosenstein, Met. Finish. (January 1990) 17-21.

[8] F.I. Nobel, R. Barnet Ostrow, D.N. Schram, "Bath and process for plating lead and tin/alloys", U S Patent 4,565,610, assigned to Lea Ronal Inc., 21 January 1986.

[9] C.T.J. Low, Rotating electrodes: the electrodeposition of tin and tin-copper alloys(PhD Thesis) University of Southampton, UK, February 2007.

[10] C.T.J. Low, F.C. Walsh, Trans. Inst. Met. Finish. (2014) (submitted for publication).

[11] C.T.J. Low, C. Kerr, C. Ponce-de-León, F.C. Walsh, Ch. 13 in: U.S. Mohanty (Ed.), Electrodeposition: Properties, Processes and Applications, Nova Publishers, New York, 2012, pp. 283-296.

[12] Y.-H. Yau, J. Electrochem. Soc. 147 (2000) 1071-1076.

[13] C.T.J. Low, C. Kerr, B.D. Barker, J.R. Smith, S.A. Campbell, F.C. Walsh, Trans. Inst. Met. Finish. 86 (2008) 148-152.

[14] C.T.J. Low, F.C. Walsh, Electrochim. Acta 53 (2008) 5280-5288.

[15] C.T.J. Low, F.C. Walsh, J. Electroanal. Chem. 615 (2008) 91-102.

[16] N.M. Martyak, R. Seefeldt, Electrochim. Acta 49 (2004) 4303-4311.

[17] S. Ahmed, H. Deligianni, H. Deligianni. US Patent application 20120055801, Gallium electrodeposition processes and chemistries, assigned to IBM Corp, 08 March 2012.

[18] C.T.J. Low, F.C. Walsh, Surf. Coat. Technol. 202 (2008) 3050-3057.

[19] S. Masaki, H. Inoue, H. Honma, Met. Finish. (January 1998) 16-20.

[20] N. Martyak, "Electroplating of low stress nickel", European Patent EP 089208 A2, assigned to Atotech, 18 June, 1997

[21] G.E. Shahin, "Mixtures of nickel salts of alkylsulfonic acid and reducing agents such as hypophosphorous acid, used for coating alloy substrates", US Patent 20,030,232,148 A1, assigned to G.E. Shahin, 18 June, 2002.

[22] R. Sekar, S. Jayakrishnan, Trans. Inst. Met. Finish. 90 (2012) 324-329.

[23] P.K. Leung, X. Li, C. Ponce de Léon, L. Berlouis, C.T.J. Low, F.C. Walsh, RSC Adv. 2 (2012) 10125-10156.

[24] X. Li, D. Pletcher, C. Ponce de Léon, F.C. Walsh, R.G.A. Wills, in: C. Menictas, M. Skyllas-Kazacos, T.M. Lim (Eds.), Advances in Batteries for Large- and Mediumscale Energy Storage: Applications in Power Systems and Electric Vehicles, Woodhead, 2014.

[25] P.K. Leung, C. Ponce de Léon, C.T.J. Low, F.C. Walsh, Electrochim. Acta 56 (2011) 6536-6546.

[26] P.K. Leung, C. Ponce de Léon, F.C. Walsh, Electrochim. Acta 80 (2012) 7-14.

[27] G. Nikiforidis, L. Berlouis, D. Hall, D. Hodgson, J. Power Sources 206 (2012) 497-503.

[28] G. Nikifordis, L. Berlouis, D. Hall, D. Hodgson, Electrochim. Acta 113 (2013) 412-423.

[29] W.J. Boettinger, C.E. Johnson, L.A. Bendersky, K.-W. Moon, M.E. Williams, G.R. Stafford, Acta Mater. 53 (2005) 5033-5050.

[30] K. Tsuji, K. Obata, T.T. Akashi, H. Nawafine, T.N. Kobe, "Plating bath and process for depositing alloy containing tin and copper", US 6,607,653, 22 September, 2000 assigned to Daiwa Fine Chemicals Co Ltd.

[31] C.T.J. Low, F.C. Walsh, Surf. Coat. Technol. 202 (2008) 1339-1349.

[32] C.T.J. Low, F.C. Walsh, Trans. Inst. Met. Finish. 86 (2008) 315-325 (34).

[33] N. Pewnim, S. Roy, Electrochim. Acta 90 (2013) 498-506.

[34] P.L. Cavallotti, A. Monzani, V. Sirtori, G. Zangari, “Using tin solder alloy; soldering onto copper substrate", US 5,759,379, 02 June 1998, assigned to IBM.

[35] Y. Goh, A.S.M.A. Haseeb, M. Faizul, M. Sabri, Electrochim. Acta 90 (2013) 265-273.

[36] N. Uchiyama, M. Kohinata, A. Masuda, Y. Okuhama, S. Masaki, M. Yoshimoto, Eur. Pat. Appl. (1996) (EP 690149 A1 19960103).

[37] K. Tsunoda, T. Tamura, "Tetravalent tin salt of metastannic acid and a trivalent indium salt of an organosulfonic acid, chelating agent, a caustic alkali; cyanidefree smoothness", US 6,331,240, 18 December, 2001.

[38] F.I. Danilov, V.S. Protsenko, E.A. Vasil'eva, O.S. Kabat, Trans. Inst. Met. Finish. 89 (2011) 151-154.

[39] C.T.J. Low, F.C. Walsh, Trans. Inst. Met. Finish. (2014) (in preparation).

[40] S. Rekha, K.N. Srinivasan, S. John, Trans. Inst. Met. Finish. 88 (2010) 215-219.
[41] G.E. Shahin, “Electroless nickel plating solutions”, U S Patent US 20,030,232,148 A1, assigned to G.E. Shahin, 18 June 2002.

[42] K.N. Srinivasan, S. John, J. Alloys Compd. 486 (2009) 447-450.

[43] E. Huttunen-Saarivirta, Surf. Coat. Technol. 160 (2002) 288-294.

[44] A.M. Couper, D. Pletcher, F.C. Walsh, Chem. Rev. 90 (1990) 837-865.

[45] X. Li, D. Pletcher, F.C. Walsh, Chem. Soc. Rev. 40 (2011) 3879-3894.

[46] D. Pletcher, H. Zhou, G. Kear, C.T.J. Low, R.G.A. Wills, F.C. Walsh, J. Power Sources 180 (2008) 630-634.

[47] C.T.J. Low, D. Pletcher, F.C. Walsh, Electrochem. Commun. 11 (2009) 1301-1304

[48] I. Sirés, C.T.J. Low, C. Ponce de León, F.C. Walsh, Electrochem. Commun. 12 (2010) 70-74.

[49] I. Sirés, C.T. Low, C. Ponce de León, F.C. Walsh, Electrochim. Acta 55 (2010) 2163-2172.

[50] P. Perret, Z. Khani, T. Brousse, D. Belanger, D. Guay, Electrochim. Acta 56 (2011) 8122-8128.

[51] F.J. Recio, P. Herrasti, I. Sires, A.N. Kulak, D.V. Bavykin, C. Ponce de León, F.C. Walsh, Electrochim. Acta 56 (2011) 5158-5165.

[52] D.R.P. Egan, C.T.J. Low, F.C. Walsh, J. Power Sources 196 (2011) 5725-5730.

[53] X. Li, D. Pletcher, F.C. Walsh, Electrochim. Acta 54 (2009) 4688-4695.

[54] C.T.J. Low, S.H. Hambali, C. Ponce de Leon, F.C. Walsh, Electrochim. Acta (2014) (submitted for publication).

[55] T.A. Skotheim, R.L. Elsenbaumer, J.R. Reynolds (Eds.), Handbook of Conducting Polymers, Marcel Dekker, New York, 1998.

[56] A.F. Diaz, K.K. Kanazawa, G. Gardini, Chem. Soc. Chem. Commun. (1979) 635-640.

[57] S.A. Campbell, J.R. Smith, Y. Li, S. Breakspear, F.C. Walsh, Trans. Inst. Met. Finish. 85 (2007) 237-244.

[58] G.G. Wallace, G.M. Spinks, L.A.P. Kane-Maguire, P.R. Teasdale, Conductive Electroactive Polymers Intelligent Polymer Systems, 2nd edn CRC Press, 2002.

[59] S.A. Campbell, J.R. Smith, Y. Li, S. Breakspear, F.C. Walsh, Trans. Inst. Met. Finish. 85 (2008) 34-40.

[60] R.B. Kaner, in: R.G. Linford (Ed.), Elsevier Applied Science, Essex, England, 1990, p. 97

[61] L.F. Warren, D.P. Anderson, J. Electrochem. Soc. 134 (1987) 101-105.

[62] V. Caramia, F.C. Walsh, C. Ponce de Leon, C.T.J., Low, Trans. Inst. Metal. Finish (2014) (submitted for publication).

[63] J. Tietje-Girault, C. Ponce de Leon, F.C. Walsh, Surf. Coat. Technol. 201 (2007) 6025-6034.

[64] L.S. Tan, S.R. Simko, S.J. Bal, R.A. Vaia, B.E. Taylor, M.D. Houtz, M.D. Alexander, R.J. Spry, J. Polym. Sci. B Polym. Phys. 39 (2001) 2539-2548.

[65] J. Lukkari, A. Viinikanjola, M. Salomaki, T. Aaritalo, J. Kenkatre, Synth. Met. 121 (2001) 1403-1404

[66] C.T.J. Low, R.G.A. Wills, F.C. Walsh, Surf. Coat. Technol. 201 (2006) 371-383.

[67] C.T.J. Low, J.O. Bello, J.A. Wharton, R.J.K. Wood, K.R. Stokes, F.C. Walsh, Surf. Coat. Technol. 205 (2010) 1856.

[68] E.A. Vasil'eva, I.V. Smenova, V.S. Protsenko, T.E. Konstantinova, F.I. Danilov, Russ. J. Appl. Chem. 86 (2013) 1735-1740 (2014, 87, 119).

[69] F. Zhao, S. Franz, A. Vicenzo, P.L. Cavallotti, M. Sansotera, W. Navarrini, Electrochim. Acta 56 (2011) 9644-9651.

[70] K. Helle, F.C. Walsh, Trans. Inst. Met. Finish. 75 (1997) 53-58.

[71] F.C. Walsh, C. Ponce de Leon, Trans. Inst. Met. Finish. 92 (2014) 83-98.

[72] P. Herrasti, A.N. Kulak, D.V. Bavykin, C. Ponce de Léon, J. Zekonyte, F.C. Walsh, Electrochim. Acta 56 (2011) 1323-1328.

[73] S.H. Hosseini, P. Noor, Iran. Polym. J. 14 (2005) 55-60.

[74] D.V. Bavykin, F.C. Walsh, Titanate and titania nanotubes: synthesis, properties and applications, Royal Society of Chemistry Nanoscience and Nanotechnology Monograph2009.

[75] D. Gong, C.A. Grimes, O.K. Varghese, W. Hu, R.S. Singh, Z. Chen, E.C. Dickey, J. Mat Res. 16 (2001) 3331-3334

[76] J.M. Macák, H. Tsuchiya, P. Schmuki, Angew. Chem. 44 (2005) 2100-2102.

[77] C.T.J. Low, M. de la Toba Corral, F.C. Walsh, Trans. Inst. Met. Finish. 89 (2010) 44-50

[78] C.T.J. Low, C. Ponce de Leon, F.C. Walsh, J. Appl. Electrochem. 42 (2014) 169-177.

[79] C.T.J. Low, C. Ponce de Leon, F.C. Walsh, Electrochem. Commun. 22 (2012) 166-169.

[80] F.C. Walsh, C. Ponce de Leon, D.V. Bavykin, C.T.J. Low, S. Wang, Trans. Inst. Met. Finish. (2014) (submitted for publication).

[81] L.P. Bicelli, B. Bozzini, C. Mele, L. D'Urzo, Int. J. Electrochem. Sci. 3 (2008) 356-408.

[82] C.A. Grimes, G.K. Mor, $\mathrm{TiO}_{2}$ Nanotube Arrays: Synthesis, Properties and Applications, Springer, New York, 2009.

[83] K. Lee, D. Kim, S. Berger, R. Kirchgeorg, P. Schmuki, J. Mater. Chem. 22 (2012) 9821-9825.

[84] H. Deligianni, L.T. Romankiw, R. Vaidyanathan, US Patent 2011/0108115A1, "Forming a photovoltaic device", May 12, 2011, assigned to IBM.

[85] R. Freudenberger, A. Zielonka, M. Funk, P. Servin, R. Haag, T. Valkova, U. Landau, Gold Bull. 43 (2010) 169-180.

[86] F.C. Walsh, C.T.J. Low, "Alternating Cu and Sn multilayers electrodeposited from methanesulfonic acid", unpublished.

[87] K.S. Novoselov, A.K. Geim, S.V. Morozov, D. Jiang, Y. Zhang, S.V. Dubonos, I.V Grigorieva, A.A. Firsov, Science 306 (2004) 666-669.

[88] C.T.J. Low, F.C. Walsh, M.H. Chakrabarti, M.A. Hashim, M.A. Hussain, Carbon 54 (2013) 1-21

[89] D. Van Thanh, L.J. Li, C.-W. Chu, P.J. Yen, K.H. Wei, RSC Adv. 4 (2014) 6946-6949.

[90] G. Wang, B. Wang, J. Park, Y. Wang, B. Sun, J. Yao, Carbon 47 (2009) 3242-3246.

[91] N. Liu, H. Wu, Y. Liu, C. Zhang, J. Chen, Adv. Funct. Mater. 18 (2008) 1518-1525.

[92] F.C. Walsh, C. Ponce de Leon, C.T.J. Low, unpublished work.

[93] Y. Wang, Z. Shi, J. Yin, J. Mater. Chem. 21 (2011) 11371-11377.

[94] D.V. Bavykin, L. Passoni, F.C. Walsh, Chem. Commun. 49 (2013) 7007-7009. 